\title{
How Physical Presence Overrides Emotional (Coping) Effects in HRI: Testing the Transfer of Emotions and Emotional Coping in Interaction with a Humanoid Social Robot
}

\author{
Marloes L. C. Spekman ${ }^{1,2}$ (D) Elly A. Konijn ${ }^{1}$ (D) Johan F. Hoorn ${ }^{1}$ (D)
}

Accepted: 26 March 2020 / Published online: 26 April 2020

(c) The Author(s) 2020

\begin{abstract}
The increasing pressure on healthcare systems calls for innovative solutions, such as social robots. However, healthcare situations often are highly emotional while little is known about how people's prior emotional state may affect the perception and acceptance of such robots. Following appraisal theories of emotion, the appraisal of coping potential related to one's emotions was found to be important in acting as mediator between emotional state and perceptions of a robot (Spekman et al. in Comput Hum Behav 85:308-318, 2018. https://doi.org/10.1016/j.chb.2018.03.043; in Belief in emotional coping ability affects what you see in a robot, not the emotions as such, Dissertation, Vrije Universiteit Amsterdam, Amsterdam, 2018), though this has not yet been tested in relation to actual emotional coping nor in an actual encounter with a robot. Hence, the current study focused on how actual emotional coping influences subsequent robot perceptions in two experiments. In Study $1(N=101)$ and Study $2(N=110)$ participants encountered a real humanoid robot after a manipulation to induce various emotions and coping potential. Manipulations in both studies were effective, yet the results in Study 1 were potentially confounded by a novelty effect of participants' first encounter with a real robot that talked to them. Therefore, in Study 2, participants interacted briefly with the robot before the actual experiment. Results showed an interaction effect of prior emotions and (manipulated) coping potential on robot perceptions, but not the effects expected based on previous studies. An actual interaction with a robot thus seems to provoke different reactions to the robot, thereby overruling any emotional effects. These findings are discussed in light of the healthcare context in which these social robots might be deployed.
\end{abstract}

Keywords Social robot $\cdot$ Emotion $\cdot$ Coping $\cdot$ Appraisal $\cdot$ Healthcare

\section{Introduction}

Increasing pressure on both acute and long-term healthcare due to growing elderly populations worldwide [3] combined with severe budget cuts force societies to look for solutions to relieve some of this pressure on healthcare systems. These solutions may partly be found in the field of new communication technologies. A highly promising new development in this regard is social robotics, which has thus far shown to

Marloes L. C. Spekman

mlcspekman@gmail.com

1 Department of Communication Science, Media Psychology Program, Vrije Universiteit Amsterdam, Amsterdam, The Netherlands

2 Present Address: Department of Sociology, Vrije Universiteit Amsterdam, De Boelelaan 1105, 1081 HV Amsterdam, The Netherlands enhance (social) interaction to relieve loneliness, to increase therapy adherence (i.e., remind people to take medication), and to motivate people to stay fit [4-7]. Social robots may play a supportive role as interaction partners in future healthcare. Therefore, it seems important and timely to study how individuals perceive and accept such robots as interaction partners or a social entity.

Many studies on perceptions of social robots focus on how people feel about the robot after they have interacted with the social robot. Relatively little attention has thus far been paid to the effect that prior (or so-called 'incidental') emotions may have on people's perceptions of such robots, while a study among residents of a retirement village showed that prior negative perceptions of robots may prevent people from interacting with robots in the first place [8]. The idea that prior emotional states and attitudes may affect people's perceptions of robots is further supported by findings from a study by Broadbent and colleagues [9] in which they 
compared blood pressure readings performed by a robot to those performed by medical students. Their findings showed that participants were less comfortable with the robot and thought its blood pressure readings were less accurate than the medical students' blood pressure readings, even though there were no actual statistical differences in the accuracy of both blood pressure readings. Additionally, they found that positive prior emotions and attitudes about robots in general had positive effects on perceptions of the medical robot, which may in turn affect acceptance and actual use of such robots. This might be particularly relevant in a healthcare context, as many healthcare situations go hand in hand with intense, often negatively toned emotions (e.g., feeling sad or angry after losing one's physical ability or being anxious for a pending diagnosis). Thus, it is likely that such intense emotional states affect subsequent perceptions of (interactions with) a healthcare robot.

Hence, how might these prior emotional states affect perceptions? According to appraisal theory, each emotional situation is characterized by a set of distinct appraisals [10]. Following the appraisal-tendency framework [11, 12], (incidental) emotions may influence perceptions of future, unrelated situations via the transfer of appraisals of the current (emotional) situation to those of future situations. For instance, anger is characterized by appraisals of high novelty, very high outcome certainty, goal obstruction, high urgency, other agency, and high control [13]. These anger appraisals can then transfer to a future (unrelated) situation, leading to behaviors that are in line with anger appraisals (e.g., higher risk-taking, cf. [11]). In other words, a given situation is appraised in a certain way and these appraisals may transfer to an unrelated situation in the future. Please, note that the appraisal-tendency framework refers specifically to transfer of emotions between situations that are not related to one another. For instance, anger-associated appraisals experienced because of an argument at work might consequently affect the person's appraisal of a situation that happens in traffic on the way home, for example, by taking more risk and running a red light.

Previous studies that applied this appraisal-tendency framework to study the role of emotions in interactions with healthcare robots found that especially the appraisal of coping potential played an important role, as it was found to mediate the effects of emotions on perceptions of social healthcare robots [1, 2]. Particularly, if people believed that they could cope with an emotional situation, they were more positive about the robot. Yet, those previous studies applied a procedure in which the participants were asked how they would respond to meeting a robot after reading either a newspaper article about the robot or watching on-screen videos of the robot. It is, however, well-conceivable that interacting with an actual, real-life humanoid robot may evoke more intense or even different responses. Therefore, in the current study, we examined the same idea of applying the appraisal-tendency framework to human-robot-interaction, but this time the participants were interacting with real-life robots rather than reading a newspaper article about a robot or watching video footage of a robot. Thus, this study was guided by the following research question (RQ1): How is the appraisal of coping potential related to perceptions of a humanoid healthcare robot?

Because the appraisal of coping potential is closely related to actual coping [14], we considered it important to examine what role actual coping plays in the effect of emotion on perceptions of a healthcare robot. Lazarus [14, 15] distinguishes two major types of coping strategies: problem-focused coping strategies, which are basically aimed at changing the situation, and emotion-focused coping strategies, which are aimed at changing the emotional experience itself. Imagine, for example, a situation in which you are angry because the plumber did not fix the pipes properly. Problem-focused coping strategies in this case could be fixing the pipes yourself or calling a different plumber to do it for you, while an emotionfocused coping strategy might be to call the plumber and yell at him in order to vent your anger. Generally speaking, people who feel in control over a situation and think that they are able to change the situation will use problem-focused coping strategies, whereas people who feel they lack control over the situation or are unable to change the situation are inclined to use emotion-focused coping strategies [14, 16-18]. Since the appraisals of control and coping potential are closely related, it seems logical that a high potential to cope is related to more control, and consequently also to the choice of coping strategies. Following the above, we expect that a high potential to cope with an emotional situation will be related to the use of problem-focused coping strategies, whereas a low coping potential will be related to the use of emotion-focused coping strategies (H2).

Furthermore, we expect the use of coping strategies to be related to perceptions of a social robot in a similar fashion as the appraisal of coping potential in previous studies [1, 2]. In those studies, the appraisal of coping potential was found to mediate the effect of emotion on perceptions of the robot. Following the appraisal-tendency framework and the mechanism described above, we expect that problemfocused coping strategies are used when coping potential is high (cf. H2), and consequently leads to more positive perceptions about the social robot (cf. RQ1), whereas the use of emotion-focused coping strategies would have the opposite effect. Thus, the use of problem-focused coping strategies is expected to be positively related to perceptions of a healthcare robot (H3a). By contrast, a negative relationship is expected for the use of emotion-focused coping strategies (H3b). 


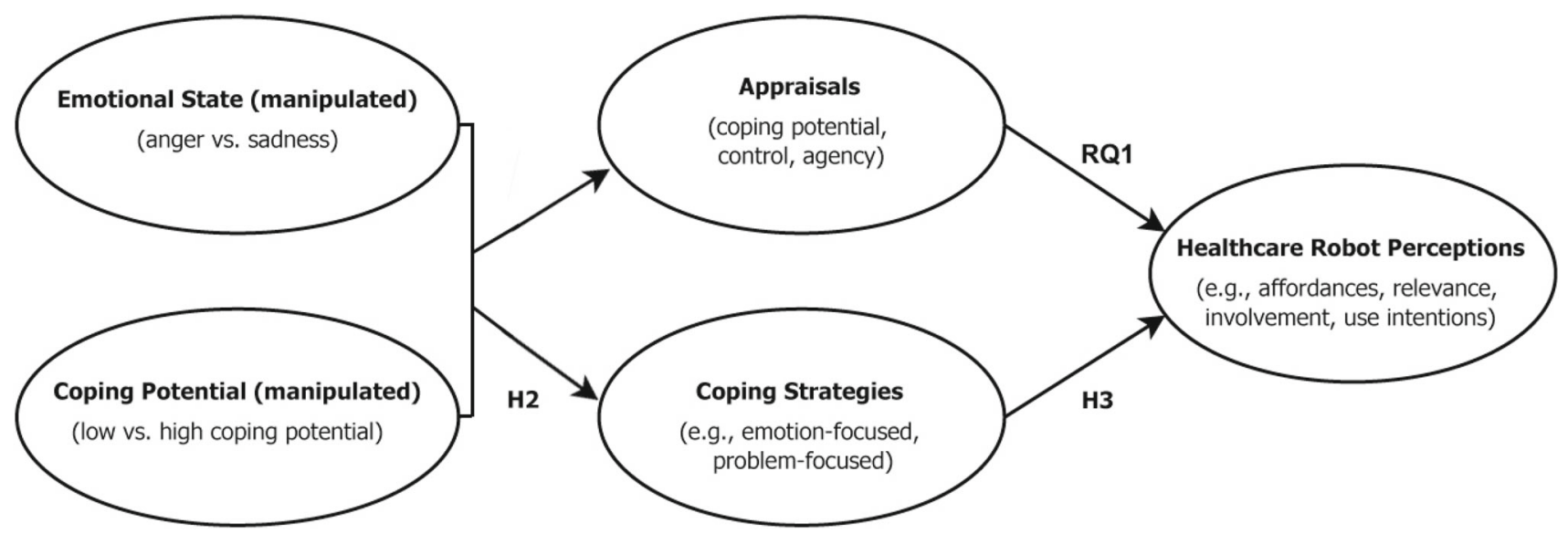

Fig. 1 Graphical representation of the theoretical framework used in the current studies

\section{Study 1}

In order to test the hypotheses and research question, emotional state and coping potential were manipulated. We chose to induce two different emotional states, anger and sadness, as they both often occur in healthcare contexts (based on informal interviews with healthcare professionals and literature, e.g., [19]). Furthermore, the literature showed that these emotions differed from each other on the appraisal of coping potential (among others): Angry people generally blame others and experience a high potential to cope with the situation, while sad people in general appraise their situation as being low in (problem-focused) coping potential [20, 21]. These emotional states were induced using a scenario method which is described in more detail in the Methods section below. Coping potential was manipulated by an appendix to this scenario which created either a changeable/controllable situation (i.e., creating a high potential to cope with the situation) or an uncontrollable situation (i.e., low coping potential). A graphical overview of the study is found in Fig. 1.

\section{Methods}

In this methods section, we report on our sample (and how we determined sample size before the start of the study), all manipulations, and all measures that were used in the study.

\subsection{Participants and Design}

A total of 101 students of the Vrije Universiteit Amsterdam in the Netherlands (74.3\% female, $M_{\text {age }}=21.38, S D_{\text {age }}=6.77$ ) were randomly assigned to one out of four conditions in a 2 (induced emotion: sadness vs. anger) $\times 2$ (manipulated coping potential: low vs. high) between-subjects lab experiment. Participants received either course credit or a gift certificate in return for their participation. No differences were found between conditions in terms of age, education, sex, and familiarity with robots in general. As determined prior to the start of the study, inclusion of participants was stopped after each experimental condition contained at least 25 participants.

\subsection{Manipulation}

Emotional state and coping potential were manipulated using a scenario method. The scenarios for emotional state were similar to those used in [22]: Participants in the sad condition imagined being present at their best friend's funeral, whereas participants in the angry condition imagined a fellow student in their group freeriding and subsequently blaming the participant for freeriding, resulting in a lower grade for the participant (see "Appendix 1" for complete scenarios).

To manipulate coping potential, an extra paragraph was added to the emotional scenario. Based on the idea that coping potential is high when the situation is changeable/controllable [14], we added a paragraph that (fictitiously) either enabled the participant to change something about the imagined scenario or a paragraph showing the participant's inability to change or control the situation (cf. [20]). For the sad condition, low coping potential was manipulated by adding that the friend's death was very sudden and tragic, whereas high coping potential was manipulated by adding that the friend had been sick and suffering for a long time and that dying was probably a relief for him/her. In the angry condition, we added either that the teacher had finalized the grades already and nothing else could be done about the situation (i.e., low coping potential) or that the teacher did not finalize the grades yet and the participant found a phone number to contact the teacher to talk about it (i.e., high coping potential).

These four scenarios were pre-tested among 62 university students (different from the participants in the actual study) to 

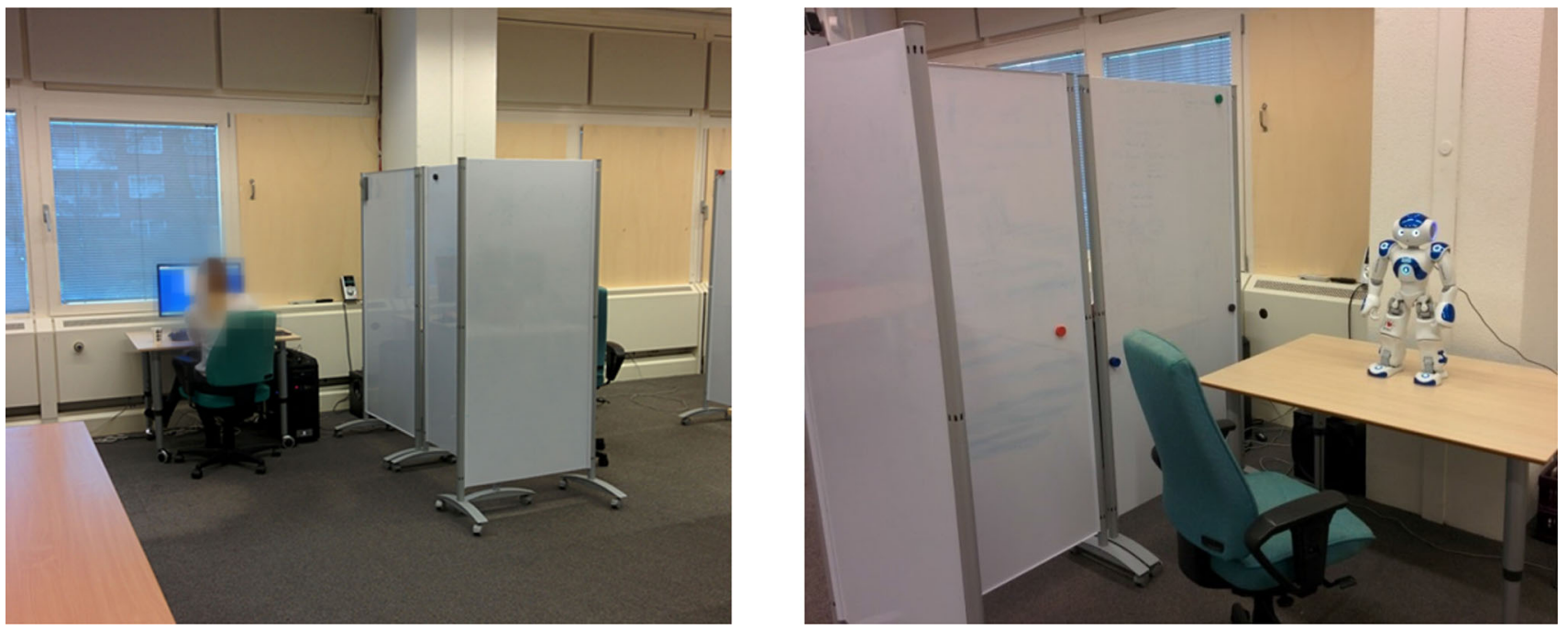

Fig. 2 Experimental setup: a participant (blurred) filling out the questionnaire at desk 1 (left image), and desk 2 on the other side of the divider screens for the participant's conversation with robot Zora (right image)

check whether the scenarios induced the intended emotional states and levels of coping potential. Results showed that participants indeed experienced the intended emotional states and different levels of coping potential (see "Appendix 2" for an overview of pre-test results).

\subsection{Procedure}

University students from various disciplines were recruited on campus to participate in a study about imagining and dealing with emotional situations. They were not informed about the role of the robot in the study. Upon entering the lab and providing informed consent, participants were seated behind a computer and asked to read and follow on-screen instructions closely (see Fig. 2, left image). Participants were then instructed to imagine as vividly as possible their assigned emotional scenario as if the situation really happened to them. After reading the emotional scenario, participants were asked to ruminate and describe their feelings about the situation (cf. [22]), and to report the intensity of their anger and sadness. Next, participants were presented with one of the coping potential manipulation paragraphs (i.e., low vs. high coping potential), followed by measures to assess their appraisals and the coping strategies that participants would use to deal with the emotional situation they had just imagined.

At this point, participants were instructed to go to another desk, separated from the first desk by divider screens (see Fig. 2, right image). On this desk, a humanoid Nao-robot Zora was awaiting the participant and opened the conversation. Nao is a humanoid, bi-pedal robot measuring $58 \mathrm{~cm}$ in height (see Fig. 2, right), created by SoftBank Robotics, and Zora is a version of the Nao robot that is combined with the user-friendly software developed by the Belgian company
QBMT/Zorabots. Up until this moment, participants were unaware that they would interact with a physically present robot. The robot introduced itself as Zora, and started talking to the participant via a Wizard-of-Oz protocol. In a Wizardof-Oz protocol, the robot is controlled from a distance by a researcher instead of functioning autonomously [23]. The conversation with Zora about the participant's health and wellbeing was pre-scripted and was based on the Manchester Short Assessment of Quality of Life questionnaire [24]. Thus, the robot acted as if it were a doctor's assistant preparing a diagnosis. Participants' answers to Zora's questions were only used by the experimenter to inform Zora's next question and to provide answers (i.e., they were not part of data collection).

After talking to the robot, participants were instructed to return to the first desk to evaluate the interaction and answer questions about their perceptions of robot Zora. Participants were then given the opportunity to provide feedback on Zora and healthcare robots in general, followed by measurements of demographics and familiarity with robots. Finally, participants were debriefed and thanked for their participation.

\subsection{Measures}

All measures used to test hypotheses are discussed below, and a complete overview of all measures used in this study (and the next) can be found on the project's OSF page (https:// osf.io/an5gr/).

Manipulation check of induced emotions. Intensity of anger and sadness experienced after imagining the emotional scenario was assessed using 1 item for each emotional state. Participants were asked to indicate the extent to which they 
experienced anger or sadness using a slider ranging from 0 ("not at all") to 100 ("very strongly").

Appraisals of coping potential and related appraisals The available scales in the literature appeared not very appropriate for our study's purposes, either because they were confounded with the assessment of other appraisals (such as power, agency, or control, cf. [13]), or because they were focused specifically on emotion-focused or problem-focused coping potential. As we aimed for a more general measure of coping potential, such scales [e.g., 13, 25] provided the base for creating a 5-item scale to assess the general appraisal of coping potential (e.g., "I think it will be tough to deal with this situation"). Answers were given on 5-point rating scales ( $1=$ fully disagree; $5=$ fully agree $)$. After recoding two negatively worded items, the 5 items together formed a reliable scale (Cronbach's $\alpha=.88$ ). A full overview of all appraisal scales and items can be found in "Appendix 3", Table 1.

Closely related to the appraisal of coping potential are appraisals of agency and control [26]. The items assessing the appraisal of agency were based on previous works $[13,26]$ and covered other-agency (single item; "something or someone else than me is responsible for this situation"), self-agency (single item; "I myself am responsible for this situation"), and situational agency ( 2 items; ${ }^{1}$ e.g., "the situation was caused by circumstances beyond human control"; $R_{\text {Spearman-Brown }}=.86$ ). The control appraisal was measured using 2 items (e.g., "I am convinced that I can change this situation"), which together formed a reliable scale $\left(R_{\text {Spearman-Brown }}=.88\right)$. All these appraisal measures were assessed using 5-point rating-scales, ranging from 1 (fully disagree) to 5 (fully agree).

Perceptions about robot Zora Perceptions about the robot were assessed by means of a framework for Interactively Perceiving and Experiencing Fictional Characters (I-PEFiC; e.g., [27]). A total of 39 statements were used to assess the 9 dimensions of the I-PEFiC framework. The degree of fit with the participant's perception of robot Zora was given per statement on 5-point rating scales $(1=$ "does not fit at all"; 5 = "fits very well"). Statements were both positively and negatively worded and the latter were recoded before analyses. We briefly describe the scales below, a full overview of the scales and items used can be found in "Appendix 3", Table 2.

Perceived ethics of Zora was assessed by means of 4 statements. The items formed a reliable scale (Cronbach's $\alpha=$ .71). Perceived affordances of Zora was assessed using 7 items, four of which formed an optimal scale (Cronbach's $\alpha=.81)$. Perceived aesthetics of Zora was measured with 4 items (Cronbach's $\alpha=.68$ ). Perceived realism was measured

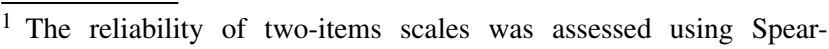
man-Brown's coefficient, as it is more appropriate than Cronbach's alpha or Pearson's coefficient for two-item scales [28].
}

using 4 items (Cronbach's $\alpha=.66$ ). Perceived relevance of the robot was measured using 4 items (Cronbach's $\alpha=$ .65). Perceived valence of Zora was assessed by means of 4 statements (Cronbach's $\alpha=.86$ ). Perceived involvement with Zora was assessed using 4 items (Cronbach's $\alpha=.84$ ). Perceived distance between the user and Zora was measured using 4 statements (Cronbach's $\alpha=.65$ ). Finally, perceived use intentions of robot Zora was assessed by means of 4 items (Cronbach's $\alpha=.74$ ).

Coping strategies We used the 28 items of the wellvalidated Brief COPE [29] to assess which coping strategies participants would use to cope with the situation they had imagined. Participants indicated for each strategy the extent to which they would perform that strategy on 5-point rating scales $(1=$ "I would certainly NOT do this", to $5=$ "I would definitely do this"). Based on results from Principal Components Analyses (PCA) and reliability analyses, we found that an 8-factor solution was most optimal (see "Appendix 3", Table 4 for an overview of items and subscales).

Problem-focused coping was assessed using 3 items (Cronbach's $\alpha=.81$ ); Support coping consisted of 4 items (Cronbach's $\alpha=.80$ ); Emotion-focused coping was also assessed by means of 4 items (Cronbach's $\alpha=.82$ ); Humor coping consisted of 2 items $\left(R_{\text {Spearman-Brown }}=\right.$ $.82)$; Denial coping was also measured by means of 2 items $\left(R_{\text {Spearman-Brown }}=.82\right)$; Self-distraction coping was measured with 2 items $\left(R_{\text {Spearman-Brown }}=.71\right)$; Substance (ab)use coping was assessed using 2 items $\left(R_{\text {Spearman-Brown }}\right.$ $=.96$ ); Spiritual coping, finally, also consisted of 2 items $\left(R_{\text {Spearman-Brown }}=.85\right)$.

\section{Results and Discussion}

\subsection{Manipulation Checks}

We checked whether our emotion manipulations were successful by running a MANOVA with the manipulated emotion and coping potential as independent variables and intensity of experienced anger and sadness as dependent variables, using IBM SPSS. Manipulation checks for intensity of emotion were successful: A multivariate effect was found for the effect of manipulated emotion on experienced emotion intensity [Wilk's $\lambda=.26, F(2,96)=139.04, p<.001, \eta_{p}^{2}=$ .74)]Univariate effects confirmed that this was the case for both intensity of experienced anger and sadness: Sad participants experienced significantly more intense sadness $(M=$ $64.45, S D=28.67)$ compared to angry participants $[M=$ 29.86, $\left.\left.S D=23.00 ; F(1,97)=47.07, p<.001, \eta_{p}^{2}=.33\right)\right]$ whereas the latter experienced significantly more anger $(M=$ $67.24, S D=18.00)$ than the first $[M=17.31, S D=19.93$; $\left.F(1,97)=166.11, p<.001, \eta_{p}^{2}=.63\right]$. No multivariate differ- 
ences were found for the coping conditions or the interaction of emotion and coping conditions (all $n s$ ) in terms of emotion intensity.

To check whether the manipulation of coping potential was successful, we performed a MANOVA with manipulated coping potential as independent variable and the appraisals (i.e., coping potential, agency, and control) as dependent variables. A significant multivariate effect was found for manipulated coping potential, Wilk's $\lambda=.71, F(5,86)=$ $6.87, p<.001, \eta_{p}^{2}=.29$. Univariate results confirmed significant effects for the appraisals of coping potential, $F(1$, $90)=4.15, p=.045, \eta_{p}^{2}=.04$, situational agency, $F(1,90)$ $=7.29, p=.008, \eta_{p}^{2}=.08$, and other-agency, $F(1,90)=$ $11.75, p=.001, \eta_{p}^{2}=.12$. No significant effects were found for control and self-agency (both $n s$ ). As expected, the high coping potential scenario was appraised as significantly easier to cope with $(M=2.97, S D=1.01)$ than the low coping potential scenario $(M=2.56, S D=.92)$. Thus, both the manipulation of coping potential and emotional state were successful.

\subsection{Testing Hypotheses}

First, we looked at the role that the appraisal of coping potential played in the effect of emotions on perceptions of a social robot (RQ1). We tested this using a two-step approach (because of the nature of our variables): (1) test for differences between conditions on the appraisal of coping potential (using MANOVA), and (2) test whether the appraisal of coping potential influenced the perceptions of the robot (using a series of regression analyses).

To test step 1, a MANOVA was performed with manipulated emotional state and coping potential as independent factors, and the appraisal of coping potential and related appraisals as dependent variables. Results showed significant multivariate effects for both manipulated emotional state [Wilk's $\left.\lambda=.19, F(5,84)=73.28, p<.001, \eta_{p}^{2}=.81\right]$ and manipulated coping potential [Wilk's $\lambda=.72, F(5,84)=$ $6.54, p<.001, \eta_{p}^{2}=28$ ] as well as the interaction of emotional state and coping potential (Wilk's $\lambda=.76, F(5,84)=5.30$, $\left.p<.001, \eta_{p}^{2}=.24\right)$. Subsequent univariate results showed several significant differences for both main and interaction effects. Because RQ1 pertained to the appraisal of coping potential in particular, we discuss here only univariate results for that appraisal - a full presentation of all multivariate and univariate results can be found in "Appendix 4". We found that emotional state as well as manipulated coping potential had significant effects on the appraisal of coping potential: Participants in the anger and high coping potential conditions appraised their potential to cope with the situation as larger than participants in the sad and low coping potential conditions $\left(p<.001, \eta_{p}^{2}=.355\right.$, and $p=.001, \eta_{p}^{2}=.109$, respectively). Similar effects were found for the appraisals of control and situational agency (see "Appendix 4").

In step 2, we tested whether the appraisal of coping potential plus the four closely related appraisals affected the perception of the robot using one regression analysis (full model using forced entry of all 5 appraisal measures at once) for each of the perception measures. Most importantly for answering our research question, we found that the appraisal of coping potential did not have an effect on any of the perception measures (all $n s$ ). A full overview of results can be found in "Appendix 4" (Table 7). The only significant effect we found, was that the appraisal of other-agency had a significant positive effect on perceived relevance of the robot, $b\left(S E_{b}\right)=.17(.05), \beta=.34, p=.002,95 \%$ CI [.06, .27]. Thus, we did find that the manipulated emotions had an effect on the appraisal of coping potential (step 1), but it did not in turn affect perceptions of the robot (step 2).

Next, we tested $\mathrm{H} 2$, which predicted that high coping potential (manipulated) would be related to the use of more problem-focused coping strategies and low coping potential (manipulated) would be related to the use of more emotion-focused coping strategies. To test this, we used a mixed-design MANOVA with manipulated emotional state and coping potential as between-subject factors, and the 8 coping strategies as within-subjects factor. Within-subjects effects were found for coping strategy, ${ }^{2} F(5.25,509.67)=$ $100.09, p<.001, \eta_{p}^{2}=.51$, and the interaction of coping strategy and manipulated emotional state, ${ }^{3} F(5.25,509.67)$ $=19.07, p<.001, \eta_{p}^{2}=.16$. Even though we hypothesized that manipulated coping potential would affect the use of coping strategies, we did not find such an effect; the interaction effect of coping strategy and manipulated coping potential was not significant, $F(5.25,509.67)=.89, p=$ $.49, \eta_{p}^{2}=.01$. Additionally, the three-way interaction of coping strategy, manipulated emotional state, and manipulated coping potential was also not significant, $F(5.25,509.67)$ $=1.66, p=.14, \eta_{p}^{2}=.02$. Thus, the effect of manipulated coping potential on the use of problem-focused and emotionfocused coping strategies as predicted in $\mathrm{H} 2$ was not found. A full overview of results (including univariate effects) can be found in "Appendix 5".

Finally, we tested whether the use of problem-focused and emotion-focused coping strategies related to the robot perception measures as expected in H3. We used a series of regression analyses (one for each of the perception measures as dependent variable) with all 8 coping strategies included

\footnotetext{
2 Degrees of freedom for this within-subject effect were corrected using the Greenhouse-Geisser correction because the assumption of sphericity was violated.

${ }^{3}$ Degrees of freedom for this within-subject effect were corrected using the Greenhouse-Geisser correction because the assumption of sphericity was violated.
} 
as predictors. Results of these analyses showed that the use of the problem-focused coping strategy was positively related to intention to use the robot, $b\left(S E_{b}\right)=.23(.11), \beta=.25$, $p=.038,95 \%$ CI $[.01, .44]$, but was not related to any of the other perception measures. Emotion-focused coping was not found to be related to any of the perception measures. Apart from distraction coping being significantly and positively related to perceived ethics of the robot $\left(b\left(S E_{b}\right)=\right.$ $.13(.07), \beta=.22, p=.045,95 \%$ CI $[.003, .26])$, none of the other coping strategies were significantly related to any of the perception measures. Thus, very limited evidence was found for $\mathrm{H} 3 \mathrm{a}$, which predicted a positive relationship between the use of problem-focused coping and perceptions of the robot, as this coping strategy was only found to be positively related to use intentions. For H3b, which predicted negative relationships between the use of emotion-focused coping and robot perceptions, we found no support, as emotion-focused coping was not related to any of the robot perception measures. Details of the analyses with regard to problem-focused and emotion-focused coping can be found in "Appendix 6".

Because these finding are in clear contrast to earlier findings $[1,2]$, we reflected on our procedure and reasoned that participants must have been surprised by interacting with a physically present robot. That is, participants were unaware that they would be meeting a robot during the study. Most participants reported that they had never talked to a robot before, and participants were clearly surprised when they were instructed to move to the second desk where Zora was located. Further inspection of the results made it clear that the results followed our expectations (i.e., emotions were induced successfully) up until the point that the participants met the robot. We assumed that such surprise evoked by the robot likely overruled any preceding effects from our manipulation procedure. Thus, this called for a second study in which we aimed to rule out such a novelty effect.

\section{Study 2}

Previous studies showed that the appraised coping potential mediated the relationship of (experimentally induced) emotions on participants' perceptions of a robot [1, 2]. However, participants in those studies were not confronted with a real, physically present robot. Rather, they saw robots in video clips or read about them in news items. In contrast, in Study 1 , reported above, the participants unexpectedly interacted with a real-life robot and then assessed their perceptions of the robot. As discussed, most participants indeed reported having been surprised about meeting the robot. This is an important lesson for subsequent studies.

In Study 2, we aimed to avoid this novelty effect that interrupted the process under study. Therefore, we deemed it important that participants would get acquainted with the robot prior to the interaction relevant for the study goals. In brief, we repeated Study 1 as closely as possible and only adjusted the procedure such that participants would already meet the robot in advance.

\section{Methods}

Similar to Study 1, we report here all information with regard to our sample (size determination), all manipulations, and all measures that were used in the study.

\subsection{Participants and Design}

A total of 110 students of the Vrije Universiteit Amsterdam in the Netherlands $\left(64.5 \%\right.$ female ${ }^{4} M_{\text {age }}=21.77, S D_{\text {age }}=$ 4.84) were, like in Study 1, randomly assigned to one out of four conditions in a 2 (induced emotion: sadness vs. anger) $\times$ 2 (manipulated coping potential: low vs. high) betweensubjects lab experiment. Before the start of the study, we determined that we would stop inclusion after the day that all experimental conditions included at least 25 participants. Participants received either course credit or a gift certificate in return for their participation. No differences were found between conditions in terms of age, education, and prior experience with robots. We found that men and women were unevenly distributed across coping potential conditions, in that men were overrepresented in the low coping potential condition and underrepresented in the high coping potential condition. However, gender was found not to have effects on any of the dependent measures, so it was not further considered.

\subsection{Procedure}

The procedure in Study 2 was identical to Study 1, except for the invitation to participate in a study to talk to a robot and that participants - who provided informed consent-had a short introductory conversation with the robot before starting the actual study. In this preparatory conversation, the robot introduced itself and asked the participant about their familiarity with robots, prior knowledge and attitudes about robots (all single items on 10-point scales, although none of these items were meant as actual measures). After this brief initial meeting, which took approximately $3 \mathrm{~min}$, the procedure was the same as in Study 1. This study took place in a different lab, however, so the lab space looked a little different. Both conversations with Zora took place on a couch (see Fig. 3, left image), while the emotion induction in between the two conversations with the robot took place at a desk a few feet

\footnotetext{
$\overline{4}$ Thus, 34.5\% male; one respondent chose not to answer the question about gender.
} 

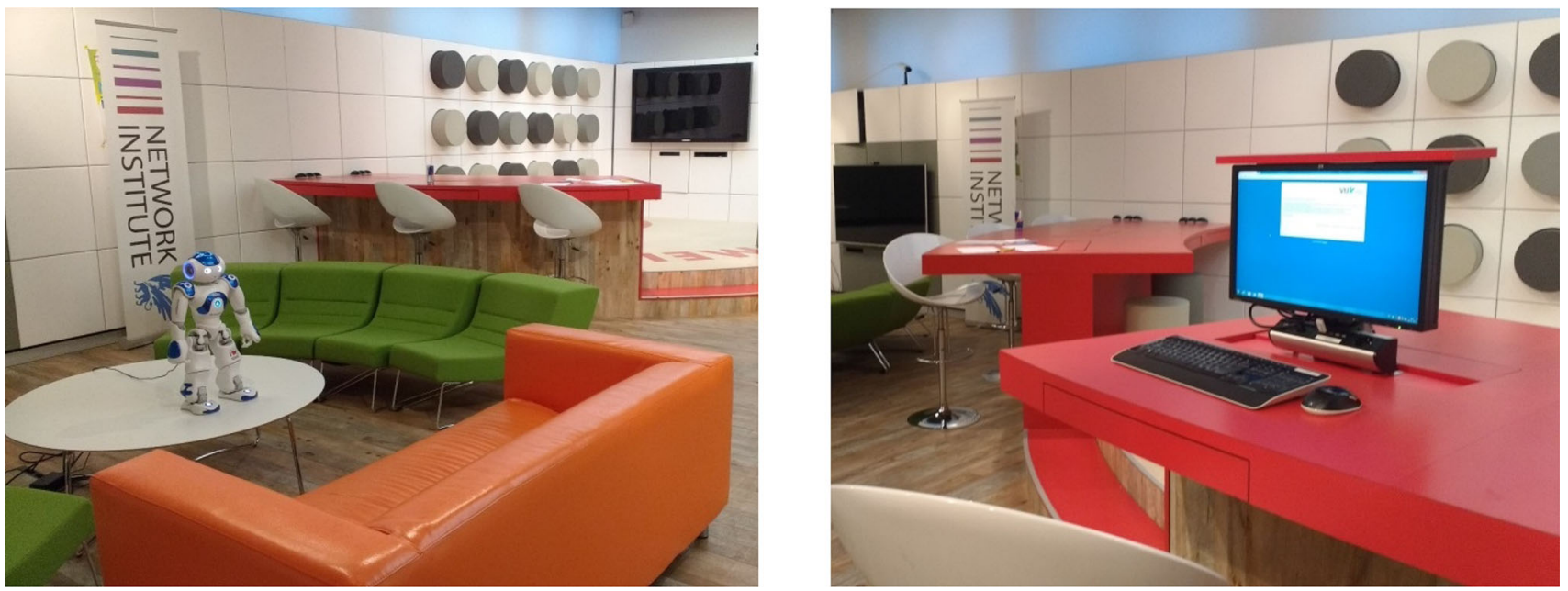

Fig. 3 Experimental setup: left side of the lab with Zora placed on a low table in front of the participant when seated on the couch (left image), and right side of the lab where the participant read the emotional scenario and filled out the questionnaire (right image)

away in the same room (see Fig. 3, right image). This is also where the participant completed the questionnaire after the conversations.

\subsection{Measures}

The measures in Study 2 were the same as in Study 1 (as were the answering options), except for some of the perception measures. Therefore, we will discuss only those scales that are dissimilar to the scales in Study 1. Because the reliability of some of the perception measures was a bit low in Study 1 , we added extra items to several scales to obtain optimal scales. After item and scale analysis, all scales were reduced to 4 items (for a full overview of scales and items there were used or not used in both studies, see "Appendix 3", Tables 1 and 3, or the OSF project page: https://osf.io/an5gr/).

Perceived ethics of Zora was assessed by means of 4 (out of 10) statements that formed a reliable scale (Cronbach's $\alpha$ $=.77)$. Perceived affordances of Zora was assessed using 4 items (out of 7) that formed an optimal scale (Cronbach's $\alpha$ $=.77$ ). Perceived aesthetics of Zora was measured with 4 items (out of 8) that constituted a sufficiently reliable scale (Cronbach's $\alpha=.67$ ). Perceived realism was measured using 4 items (out of 8) that formed a reliable scale together (Cronbach's $\alpha=.81$ ). Perceived distance between the user and Zora was measured using 4 (out of 8) statements that together formed a reliable scale (Cronbach's $\alpha=.80$ ). Finally, perceived use intentions of robot Zora was assessed by means of 4 (out of 8) items that formed a reliable scale together (Cronbach's $\alpha=.83$ ).

\section{Results}

\subsection{Manipulation Checks}

To test whether the emotional scenarios induced the intended emotion, we ran a MANOVA, using both manipulated emotion and coping potential as independent variables and experienced intensity of anger and sadness (in IBM SPSS). Multivariate results showed that the intensity of emotions experienced differed significantly between the emotion conditions [Wilk's $\lambda=.27, F(2,105)=142.94, p<.001, \eta_{p}^{2}$ $=.73]$. No differences were found in emotion intensity between the coping potential conditions or the interaction of manipulated emotion and coping potential (both $n s$ ). As expected, angry participants experienced anger significantly more intense $(M=66.58, S D=23.16)$ than sad participants $\left(M=15.44, S D=22.75 ; F(1,106)=134.69, p<.001, \eta_{p}^{2}\right.$ $=.56)$, whereas sad participants experienced sadness more intensely $(M=60.56, S D=24.68)$ than the angry participants $(M=27.93, S D=22.28, F(1,106)=49.29, p<.001$, $\left.\eta_{p}^{2}=.32\right)$. Thus, the manipulation of emotion was successful.

Another MANOVA (using manipulated coping potential as independent and appraisal measures as dependent variables) was performed to test whether coping potential was successfully manipulated. Results showed a significant multivariate effect of manipulated coping potential on appraised coping potential and related appraisals, Wilk's $\lambda=.78, F(5$, $104)=5.74, p<.001, \eta_{p}^{2}=.22$. Inspection of univariate effects showed that this multivariate effect was caused by differences between the two coping potential conditions on the appraisals of coping potential, $F(1,108)=11.20, p$ $=.001, \eta_{p}^{2}=.09$, and the appraisal of situational agency, 
$F(1,108)=4.17, p=.044, \eta_{p}^{2}=.04$. No differences were found for the appraisals of control, self-responsibility, and other-responsibility (all $n s$ ). As intended, participants in the high coping potential scenario appraised the scenario as significantly easier to cope with $(M=3.23, S D=.90)$ than participants in the low coping potential scenario $(M=2.66$, $S D=.87$ ). Thus, the manipulation of coping potential was also successful.

\subsection{Testing Hypotheses}

To answer RQ1 about the relationship between the appraisal of coping potential and the perceptions of a social robot, we used the same two-step approach as we did in Study 1: (1) Check for differences between experimental conditions in terms of appraisals (and the appraisal of coping potential in particular) using MANOVA, and (2) check whether these appraisals (and particularly the appraisal of coping potential) influenced perception measures (using a series of regression analyses).

In testing step 1, we found multivariate effects for both the main effects of manipulated emotional state [Wilk's $\lambda$ $\left.=.24, F(5,102)=65.53, p<.001, \eta_{p}^{2}=.76\right]$ and manipulated coping potential [Wilk's $\lambda=.78, F(5,102)=5.73, p$ $\left.<.001, \eta_{p}^{2}=.22\right]$, as well as a multivariate interaction effect of both [Wilk's $\lambda=.87, F(5,102)=3.13, p=.011, \eta_{p}^{2}=$ .13]. Most importantly for our research question, univariate results showed that both manipulated emotional state $[F(1$, $\left.106)=57.53, p<.001, \eta_{p}^{2}=.35\right]$ as well as manipulated coping potential significantly affected the appraisal of coping potential $\left[F(1,106)=22.01, p<.001, \eta_{p}^{2}=.17\right]$. Participants that were angry appraised their situation as easier to cope with $(M=3.49, S D=.85)$ than sad participants $(M=$ $2.48, S D=.70)$, and participants in the high coping potential condition also appraised their situation as easier to cope with $(M=3.23, S D=.90)$ than participants in the low coping potential condition $(M=2.66, S D=.87)$. See "Appendix 7" for a full overview of results from this analysis.

In step 2, we looked at the effects of the appraisal of coping potential and related appraisals on perceptions of Zora, using a series of regressions. We found no effect of the appraisal of coping potential on any of the perception outcomes. We only found that the appraisal of self-agency had a significant negative effect on the perception of Zora's valence, $b\left(S E_{b}\right)$ $=-.17$ (.09), $\beta=-.24, p=.049,95 \%$ CI $[-.34,-$ $.001]$. None of the other appraisals had significant effects on any of the perception measures, and neither did the appraisal of self-agency affect any of the other perception measures except for perceived valence (all $n s$; see "Appendix 7" for a full overview of results). Thus, we found a result similar to that in Study 1, in that our manipulation did induce coping potential, yet the appraisal of coping potential was not related to any of the robot perception measures.

Next, we tested whether $\mathrm{H} 2$, which predicted that the manipulation of coping potential would affect the use of problem-focused, emotion-focused, and related coping strategies. We used a mixed-design MANOVA with manipulated emotional state and coping potential as between-subject factors and the 8 coping strategies as within-subjects factor. Similar to Study 1, we again found within-subjects effects for coping strategy, ${ }^{5} F(5.596,593.227)=140.43, p<.001, \eta_{p}^{2}$ $=.57$, and the interaction of coping strategy and manipulated emotional state ${ }^{5}, F(5.596,593.227)=22.78, p<.001, \eta_{p}^{2}=$ .18 (see "Appendix 8" for further details about this analysis). However, this time-and most important for the hypothesis - we also found a significant interaction of coping strategy and manipulated coping potential, $F(5.596,593.227)^{5}$ $=3.81, p=.001, \eta_{p}^{2}=.04$. Pairwise comparisons (using Bonferroni correction for multiple comparisons) showed that this within-subjects interaction of coping strategies and manipulated coping potential was qualified by significant differences between the high and low coping potential conditions for only two coping strategies: denial coping and emotion-focused coping. In contrast to our hypothesis $(\mathrm{H} 2)$, which predicted a relationship between high coping potential and problem-focused coping, and between low coping potential and emotion-focused coping, we found no difference in the use of problem-focused coping strategies, and the effect found for the use of emotion-focused coping strategies was in the opposite direction than expected (i.e., participants in the high coping potential condition used more emotion-focused coping compared to their low coping potential counterparts). Furthermore, the overall between-subjects effect for manipulated coping potential was not significant. Concluding, we again did not find support for $\mathrm{H} 2$.

Finally, we tested the effect of problem-focused and emotion-focused coping strategies on participants' perceptions of robot Zora (cf. H3) using a series of regressions analyses for each of the perception measures with the coping strategies as independent variables (using 'forced entry' to add all 8 coping strategies into the model at once). With regard to the coping strategies of interest to our hypothesis (i.e. problem-focused and emotion-focused coping), we found that problem-focused coping did not affect any of the perceptions of robot Zora. Emotion-focused coping strategy had a positive relationship with perceived relevance $\left(b\left(S E_{b}\right)=.18(.07), \beta=.27, p=.016,95 \%\right.$ CI $\left.[.03, .32]\right)$ but not with any of the other perceptions of robot Zora. See "Appendix 6" for more details of this analysis, also in relation to the other coping strategies. These results thus contra-

\footnotetext{
5 Degrees of freedom for this analysis were corrected using the Greenhouse-Geisser correction because the assumption of sphericity was violated.
} 
dict $\mathrm{H} 3$, in which we expected that problem-focused coping would be positively related to perceptions about the robot and that emotion-focused coping would be negatively related to these same perceptions.

\subsection{Exploratory Analyses}

Finally, we explored potential direct effects of the conditions on the perceptions participants had about the robot. Results from a MANOVA with manipulated emotional state and coping potential as independent factors and robot perception measures as dependent variables showed that both main effects were not significant $(p=.721$ and $p=.216$ for the main effects of emotional state and coping potential respectively). However, the multivariate interaction effect of manipulated emotional state and coping potential did turn out to be significant, Wilk's $\lambda=.84, F(9,98)=2.13, p=$ $.034, \eta_{p}^{2}=.16$.

Univariate results showed that this multivariate interaction effect was caused by significant effects on perceived realism, $F(1,106)=6.18, p=.014, \eta_{p}^{2}=.06$, and perceived intentions to use the robot, $F(1,106)=4.84, p=.030, \eta_{p}^{2}=.04$. Descriptive statistics showed that among the sad participants, the ones in the high coping potential condition perceived the robot to be more realistic $(M=2.52, S D=.80)$ and had higher intentions to use it $(M=3.78, S D=.82)$ compared to the sad participants in the low coping potential condition (respectively $M=1.93, S D=.65 ; M=3.28, S D=1.00$ ). For angry participants, we found the opposite to be true: Participants in the low coping potential condition perceived more realism $(M=2.37, S D=.59)$ and had higher intentions to use the robot $(M=3.56, S D=.65)$ compared to participants in the high coping potential condition $(M=2.22, S D=.95$; $M=3.29, S D=1.07)$. These interaction effects are visualized in Fig. 4 below. Interested readers are referred to the OSF project page (https://osf.io/an5gr/) for further results of this analysis.

\section{Discussion}

The current paper aimed to study the role of emotion and emotional coping in influencing people's perceptions of social robots. Prior research focused either on emotions experienced after an interaction with a robot, or assessed perceptions of a robot without participants having actually interacted with a robot. In two studies, we examined how prior (incidental) emotions and related appraisals and coping influenced perceptions that participants formed in interaction with robot Zora.

In the first study, we did not find the results that were expected from the theoretical framework and supported in previous research on the influence of prior emotions on perceptions of robots. We did find the expected differences between conditions of emotional state and coping potential in terms of the appraisals and coping strategies associated to each of the conditions, yet we did not find the expected effects of the appraisals or coping strategies on perceptions of the robot. Based on participants' reactions after participation in Study 1, it seemed that surprise about meeting a robot during the study may have overruled the effects of appraisals and coping strategies on perceptions of the robot. In Study 2, we therefore aimed to rule out surprise as a possible hindrance for finding the expected effects. However, results of this second study also did not support the hypotheses. Even though we did find that our manipulations were effective in achieving different emotional states and different levels of coping potential and these clearly affected participants' appraisals and coping strategies, results again did not show that these appraisals or coping strategies affected the perceptions of the robot in the predicted way. Additional analyses showed some interesting interaction effects that affected perceptions of the robot. Important lessons can be learned as discussed next.

These results contrast earlier studies [1,2], which found that the appraisal of coping potential mediated the effect of emotional state on perceptions of a social robot. Those prior studies differ-among others-from the current studies in the way emotional state was induced. In both earlier studies $[1,2]$, a recall procedure was used to induce emotions, whereas the current studies used a scenario method to induce emotion. The scenarios were extensively pre-tested to check whether they successfully induced the desired emotion. Still, one could argue that there are important differences between the two emotion induction methods. The recall procedure asks participants to recall a situation in which they experienced a certain emotion, which stimulates participants to experience a personally relevant emotion. The scenario method may be less personally relevant for the participants, especially if participants are having trouble imagining the particular scenario. Even though the recall procedure is often used in emotion research and may induce personally relevant emotions, it has the disadvantage that the emotional state in question may be resolved by the time the situation is recalled (cf. goal-attainment [11]). If this is the case, then there is a big chance that the appraisals or coping strategies reported about the emotional situation have been weakened or changed (i.e., one possible coping strategy is cognitive reappraisal [30]). Both recall and scenario methods of emotion induction have their advantages and disadvantages (see, for example, [31, 32] for comparisons of different emotion induction procedures), and perhaps the difference between the two emotion induction methods may have affected the findings in the current studies to differ from those in Spekman and colleagues $[1,2]$. In our studies, however, the scenario method resulted in comparable intensities of induced emotional states as the 
Fig. 4 Interaction effects of manipulated emotional state and coping potential on participants' perceptions of the robot's realism and intentions to use the robot

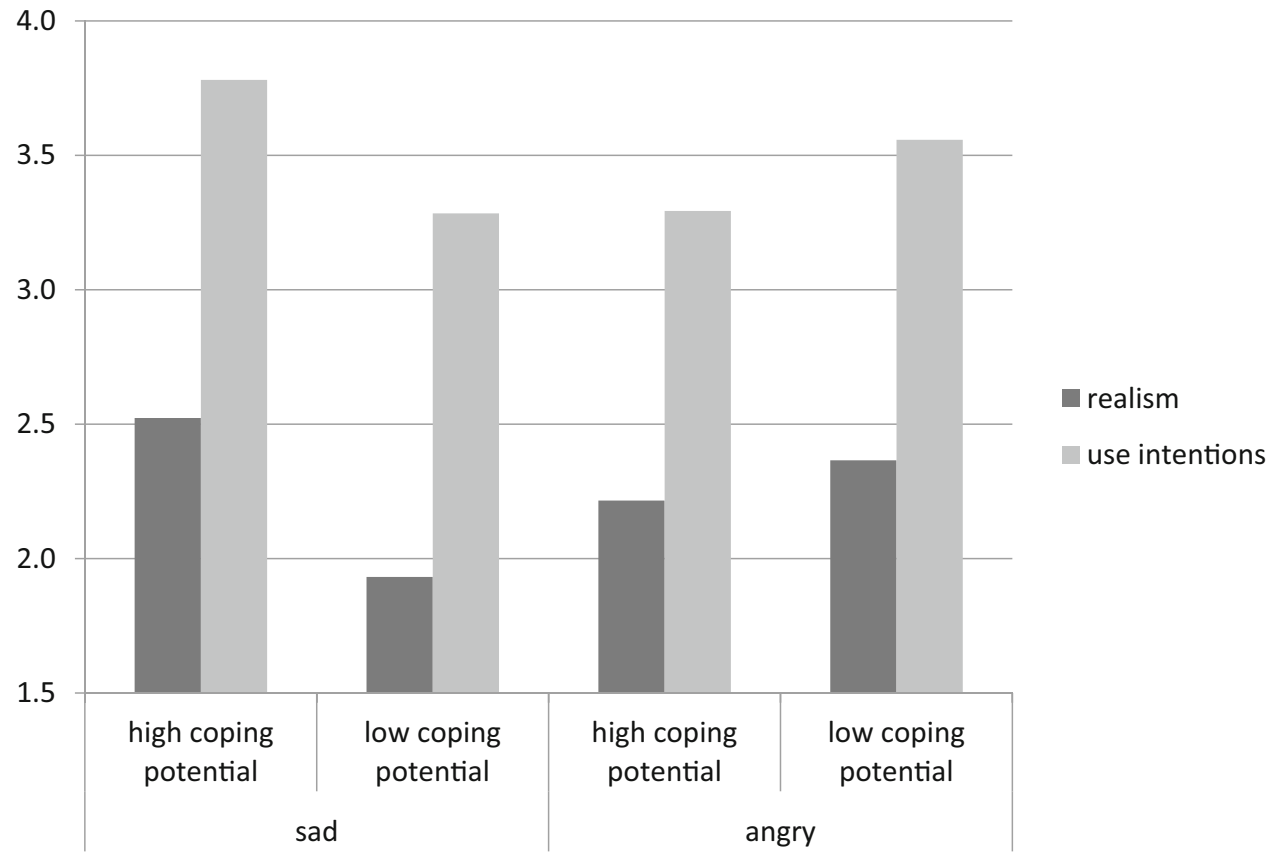

recall method in [1, 2] and our focus was on studying the effects of these emotions (i.e., not how they were induced). Importantly, one should note that the underlying mechanism of emotions influencing unrelated situations via the transfer of emotion-related appraisals (cf. the appraisal-tendency framework, $[11,12])$ should not change solely because of the way the emotion was induced. Future research could compare both methods in the same experimental design to test whether the way emotions are induced may further influence appraisal transfer processes.

As noted in the introduction, there is another difference between the current studies and earlier studies: The participants in the current studies had an actual interaction with robot Zora while this was not the case in some of those earlier studies. In the study by Spekman and colleagues [2], participants' perceptions were assessed based on their reading of a newspaper article about a robot, and in Spekman and colleagues [1], participants had a 'virtual' interaction with a robot via on-screen videos. In the two studies reported in the current paper, participants talked to robot Zora which was physically present, standing in front of the participants. It is likely that the physical presence of the robot and experience with the robot may have influenced results, as has been shown to be the case in previous research comparing physical robots to virtual, on-screen versions thereof [33-35]. In those studies, the physically present robot led to more experienced social presence, more favorable attitudes/evaluations $[34,35]$, and more time spent on the interaction [36] than the virtual on-screen version of the robot. However, none of the robots used in those studies were humanoid robots, which may be the reason why the current studies' findings do not align with findings from these previous studies. Furthermore, the tasks that participants had to perform in those studies were clearly different from the task in the current studies. In our own studies, the task was not so much presented as a task, but rather as a general conversation. This is in clear contrast to the problem-solving and persuasive tasks in earlier studies. As Hoffman and Krämer [33] showed in their study, the nature of the task can influence people's preference for a robot or a virtual, on-screen agent (i.e., the virtual agent was preferred for persuasive purposes, whereas the physical robot was preferred for problem-solving tasks). Thus, perhaps the physical presence of the robot in our studies may have resulted in a different process compared to the earlier studies by $[1,2]$. Additionally, experience with technology has been found to be a strong moderator of use intentions and actual use of that technology [36]. It is thus likely that the physical presence of the robot and actual experience affect the way we perceive robots, and consequently may overrule any emotional effects. More research is needed to say more about the relative contribution of different factors (such as prior emotions and technology experience) in influencing perceptions of social robots in healthcare contexts. Future research could, for instance, compare emotion- and coping-based responses to a virtual version of a robot versus responses to an embodied version of the robot, as well as a human interviewer, keeping the interview task consistent between conditions.

Even though we did not find that appraisals and coping strategies affected the perceptions of the robot as expected, additional analyses showed that the interaction of emotional state and coping potential had an effect on some of the measures of perceptions about the robot. This was in contrast to expectations based on the appraisal-tendency approach [11, 12], which suggested that emotional state may affect future 
situations via the transfer of emotional appraisals from one situation to another. However, at the same time, this interaction effect of emotion and coping seems to be in line with the approach to coping as suggested by Lazarus [37]. Lazarus [37] distinguishes two different appraisals for every emotional situation: a primary appraisal (is this situation important and relevant to me?) and a secondary appraisal (what can I do to cope with this situation?). Both these appraisal processes are important in determining how people feel about a situation as well as what actions people undertake to cope with that situation. The results of the current study's additional, exploratory analyses align with this approach by showing that emotional state (i.e., primary appraisal) only affects perceptions of the social robot's affordances and use intentions in combination with coping potential (i.e., secondary appraisal)—yet only for a limited number of perceptions. This seems to suggest that differences between emotional states on the perceptions of a social robot are contingent upon whether the emotional state is (relatively) easy or hard to cope with.

A point of attention with regard to our studies was a larger number of male participants in the second study compared to Study 1 (25.7\% in Study 1 vs. 34.5\% in Study 2). Additionally, the general familiarity with robots in the media as reported by the participants themselves was also higher in Study 2 than in Study $1(M=4.68, S D=2.31$ in Study 1 vs. $M=5.34, S D=1.74$ in Study 2). This may have been due to how the second study was advertised as "talking to a robot", whereas the first study was advertised as "a study about imagining and dealing with emotional situations". This may have attracted somewhat different audiences to participate in both studies and possibly led to different expectations about the robot to begin with. These expectations about the robot and its capabilities may also have interrupted the effects that emotional appraisals or coping may have had on perceptions of the robot, for instance, because the robot did not meet expectations. Future research should thus seriously consider the expectations that (potential) participants may have about the robot, especially in relation to the task that the robot and the participant will have to perform.

The conversation that participants had with robot Zora was based on the Manchester Short Assessment of Quality of Life questionnaire (MANSA [24]). To keep as close to the MANSA questionnaire as possible, the interaction was designed such that it did not allow for deviation from the pre-programmed Likert-type questions. This sometimes led to situations in which participants felt the conversation was unnatural, especially when participants asked questions in return which Zora did not reply to, or when Zora interrupted the participants. Yet, the focus of the current study was not on this interaction, but rather on seeing how perceptions of the robot would be influenced by participants' prior emotions. Nevertheless, the 'unnatural' feel of the conversation may have also affected participants' perceptions of the robot, and perhaps interrupted the expected effects of the induced emotions and coping potential. It would be valuable to further explore the participant's experience of the robot as conversation partner or social agent in future research.

Related is that the nature of the conversation with the robot was inherently artificial due to the research context. Participants were induced with an emotion (the success of which is contingent upon their willingness to engage in the scenario, to begin with), and then could only briefly interact with the robot. In actual healthcare situations, the emotions that patients experience are likely to be much more intense and longer lasting than the ones we induced in our lab, and it is likely that the emotions that we induced faded away fairly quickly, making it difficult to predict what would actually happen in a healthcare situation with more intense and longer lasting emotions, and where people have more opportunity to interact with a robot. Field experiments, in which people's emotions and coping are assessed before interacting with a robot and their behavior towards the robot is then monitored, are an important next step for better understanding the role emotion and coping play in influencing perceptions of robots.

In all, even though it may seem obvious that one's ongoing emotional state would affect how one interacts with a robot, the current studies did not find support for this idea. Interestingly, earlier studies in which the robot was not physically present did find support for that common sense expectation (albeit via emotional appraisals), so, the physical presence of the robot apparently makes a big difference. It seems as though encountering a physically present social robot engages an entirely different process, in which prior emotions play a different role. Even though more research is needed (especially in the field), the results seem to suggest that the mere presence of a robot may make us forget-at least temporarily-our emotional consternations.

Acknowledgements The authors would like to thank Lieke Tel and Pouya Zarchin with their practical help in the lab, and Marco Otte for his help with setting up the labs and equipment.

Funding This work was supported by the Creative Industry Scientific Programme of the Netherlands Scientific Organization [CRISP/NWO; Grant Number: NWO 646.000.003].

\section{Compliance with Ethical Standards}

Conflict of interest The authors declare that they have no conflict of interest.

Open Access This article is licensed under a Creative Commons Attribution 4.0 International License, which permits use, sharing, adaptation, distribution and reproduction in any medium or format, as long as you give appropriate credit to the original author(s) and the source, provide a link to the Creative Commons licence, and indi- 
cate if changes were made. The images or other third party material in this article are included in the article's Creative Commons licence, unless indicated otherwise in a credit line to the material. If material is not included in the article's Creative Commons licence and your intended use is not permitted by statutory regulation or exceeds the permitted use, you will need to obtain permission directly from the copyright holder. To view a copy of this licence, visit http://creativecomm ons.org/licenses/by/4.0/.

\section{Appendix 1: Scenarios}

\section{Sad Condition}

(Note: participants were asked first "Is your best friend male or female?", to tailor the scenario)

Today is gonna be a hard day: Saying goodbye to your best friend. It felt like a massive blow to the head when his/her parents called you to tell you s/he passed away. The first day you were very upset and you spent the entire day crying in bed. You will miss him/her and his/her support immensely...

During the farewell service, you look outside. It starts to rain. As if today wasn't sad enough yet. You look around you and see your best friend's parents. They're crying. Your eyes are burning. The hall is packed with family, friends, and fellow students. Some people even have to stand up during the service because there aren't even enough chairs. Your throat hurts. All these people are going to miss him/her so much, just like you... You feel a lump in your throat, and swallow your tears.

Your friend's mother tells a touching story about how funny s/he was as a kid, and how heavy the last period had been to her and her husband. They had asked you to speak too, but you were certain that you would have to cry if you did. And what is there to say anyway? That s/he was so incredibly nice, sweet, and funny? That you will miss him/her so much? It only makes the grief worse...

When you look around, you see that many of the speakers and other people present also have trouble to keep their eyes dry during the speeches. You feel tears filling up your eyes again and try to swallow them away.

After the service, the family walks outside with the coffin. You, and the rest of the people present follow in a procession to the spot where s/he will be buried. Once at the burial site, they hand out flowers. White roses, his/her favorite. Together with friends, you put your roses on the coffin, after which the casket is lower into the grave. You feel cold sweat on your back. The other people also put their roses on the coffin, and slowly people are leaving the cemetery.

You look into the grave. How cold it has to be down there... A shock goes through your body. Your body trembles. You will never see him/her again. You let your tears flow freely...

\section{Easy-to-Cope-with (Sad Condition)}

Your friend's passing didn't come as a total surprise. S/he was battling cancer for years, and unfortunately s/he lost the battle a few days ago. You knew it was coming. It was already clear as day when s/he was diagnosed that it would be just a matter of time.

You know that s/he was in a lot of pain, and that s/he suffered tremendously in the last few weeks. Now his/her suffering has ended, and you think this might be for the best.

\section{Hard-to-Cope-with (Sad Condition)}

Your friend's passing came as a complete surprise. Last weekend, the two of you and some other friends went out, and the next day you got a phone call from his/her parents. S/he was involved in an accident on the way to university. S/he died instantly...

A guy/girl in the prime of his life, all of sudden s/he was gone. Incredible! Life is so unfair!!!

\section{Anger Condition}

The last few weeks, you worked really hard on an important course assignment, together with a fellow student. Although... 'together' is somewhat exaggerated... Basically, you did all of the work by yourself, while your fellow student came up with one poor excuse after another.

Immediately when the teacher announced the groups, you heard that he is notorious for freeriding. You wanted to give him the benefit of the doubt, so you immediately sent him an e-mail to ask when he had time to work on the first part of the assignment together. His reply was filled with excuses. He said he had to work all week when we didn't have classes, so he really couldn't find the time this week to work on the assignment together. He suggested you could do the first part this week, and he would make up for that next week.

But of course, that didn't happen in the following week. Nor in the week thereafter. Every single time he had some kind of excuses, and after a lot of drama you did all of the assignments yourself. Fool. You are so done with that guy and don't want to waste any more energy on him. You seriously doubted whether you would put his name on the assignments, and now you regret doing it anyway. You seriously hate yourself for doing this... Fool, fool!

Then you get an e-mail from your teacher that you're the guy your worked together with - yeah right, 'together' - does not agree with the grade you two got (a C) because he claims that he did most of the work! And so he feels he is entitled to a higher grade than you! Are you kidding me?!

The teacher suggests, based on his story, that he will get a B, and you will get a D. Aaaargh! Really?! Where does he get the nerves? Your heart pounds and you clench your 
fists. I"s a good thing that guy isn't here right now, because you would've probably seriously injured him. And why does that teacher just assume that his story is true without even hearing your side of the story?! You throw the pens on your desk them across the room and tear that stupid assignment to pieces and throw the pieces across the room as well. Did they go mad?!

\section{Easy-to-Cope-with (Angry Scenario)}

How is it possible that that teacher just believes that idiot's story no questions asked, while the teacher didn't even ask for your side of the story? Luckily, the grades aren't final yet...

At the bottom of the teacher's e-mail you see a phone number-good! That gives you the opportunity to at least tell your side of the story!

\section{Hard-to-Cope-with (Angry Scenario)}

How is it possible that that teacher just believes that idiot's story no questions asked, while the teacher didn't even ask for your side of the story? And to make matters worse, it turns out that the teacher has already finalized the grades. Now it's obviously impossible to do something about it...

\section{Appendix 2: Pre-test Results}

In the pre-test, we checked whether the emotional scenarios indeed induced the intended emotion and coping potential among 62 university students.

To assess emotion, we used 4 items to check whether respondents felt angry after reading the story (Cronbach's $\alpha=.95$ ), 3 items to check whether respondents felt sad after reading the story (Cronbach's $\alpha=.88$ ), and 9 filler items representing different emotions than anger and sadness. Furthermore, intensity of experienced anger and sadness was measured using a slider $(0=$ "not angry/sad at all" to $100=$ "very angry/sad").

To test whether the two emotional scenarios induced different emotions, a MANOVA was performed with emotional condition as independent variable, and the anger-scale, the sadness-scale, and the filler items as dependent variables. Multivariate effects showed a significant effect, Wilk's $\lambda=$ $.38, F(11,50)=7.29, p<.001, \eta_{p}^{2}=.62$. Univariate effects showed a significant difference between the two conditions in terms of anger, $F(1,60)=25.86, \mathrm{p}<.001, \eta_{p}^{2}=.30$, and a marginally significant difference in terms of sadness $F(1,60)$ $=3.63, p=.06, \eta_{p}^{2}=.06$. Participants that had read the anger-scenario were thus more angry $(M=3.05, S D=1.13)$ and less $\operatorname{sad}(M=2.24, S D=.87)$ than participants that had read the sadness-scenario $(M=1.71, S D=.93$ and $M=2.70$,
$S D=1.04$ respectively). Furthermore, we also found significant yet small differences on filler items 'cheerful' $(F(1,60)$ $\left.=7.37, p=.01, \eta_{p}^{2}=.11\right)$ and 'tense' $(F(1,60)=4.66, p$ $=.04, \eta_{p}^{2}=.07 ;$; ; participants in the anger condition scored somewhat higher on both items than participants in the sadness condition.

Next, we also performed a MANOVA with emotional condition as independent and anger and sadness intensity scores as dependent variables. Multivariate tests showed a significant difference; Wilk's $\lambda=.49, F(2,59)=30.61, p<.001$, $\eta_{p}^{2}=.51$. Univariate tests confirmed that, as expected, angry participants scored higher $(M=61.65, S D=23.78)$ on the anger-intensity scale than sad participants $(M=28.84, S D=$ 25.68), $F(1,60)=27.24, p<.001, \eta_{p}^{2}=.31$. Furthermore, $\mathrm{sad}$ participants also were found to score higher on the sadnessintensity scale $(M=50.19, S D=25.40)$ compared to angry participants $(M=31.32, S D=20.96), F(1,60)=10.18, p=$ $.002, \eta_{p}^{2}=.15$.

In order to assess coping potential among the respondents, we used 5 items from Spekman et al. (2018a) to assess the appraisal of coping potential (e.g., "I trust that I can handle this situation"), which together formed a reliable scale (Cronbach's $\alpha=.87$ ). We also assessed the closely related appraisals of control ( 2 items; $R_{\text {Spearman-Brown }}=.84$ ), situational agency ( 2 items; $R_{\text {Spearman-Brown }}=.83$ ), other-agency (single item) and self-agency (single item; all items from Spekman et al., 2017a). We expected that our manipulations of coping potential would affect the appraisal of coping potential, but not the other appraisals.

To test whether the emotional scenarios differed in terms of coping potential, we performed a MANOVA with coping potential as independent variable and the appraisals as dependent variables. Even though multivariate tests showed no significant results (Wilk's $\lambda=.88, F(5,56)=1.52, p=.20$, $\eta_{p}^{2}=.12$ ), we nevertheless inspected univariate results based on our expectations that only the appraisal of coping potential would be affected by our manipulation. These results showed a significant yet small univariate effect for coping potential, $F(1,60)=5.10, p=.03, \eta_{p}^{2}=.08$. Participants that had read the easy-to-cope-with paragraph appraised their situation as somewhat easier to cope with $(M=3.18, S D$ $=1.04)$ compared to participants that had read the hard-tocope-with paragraph $(M=2.62, S D=.91)$. Results showed that these coping potential manipulations did not affect the other appraisals.

To conclude, we found that the emotional scenarios induced the intended emotions, and that the additional paragraph intended to induce coping potential also did just that while not affecting the appraisals of control or agency. Thus, we considered the manipulation successful. 


\section{Appendix 3: Overview of Scales and Items Used in Study 1 and 2}

See Tables 1, 2, 3 and 4.

Table 1 Overview of appraisal measures and their reliabilities in study 1 and 2
Table 2 Overview of the robot perception measures and their reliabilities in study 1

\begin{tabular}{|c|c|c|c|}
\hline Scale & Items used in scale & Reliability study 1 & Reliability study 2 \\
\hline Coping potential & $\begin{array}{l}\text { I know how I can best deal with this } \\
\text { situation } \\
\text { I think it will be though to deal with this } \\
\text { situation }^{\mathrm{a}} \\
\text { I think I can easily cope with this situation } \\
\text { It is unclear to me how I should handle this } \\
\text { situation } \\
\text { I trust that I can handle this situation }\end{array}$ & $.881^{\mathrm{b}}$ & $.885^{\mathrm{b}}$ \\
\hline Other agency & $\begin{array}{l}\text { Something or someone else than me is } \\
\text { responsible for this situation }\end{array}$ & N/A & N/A \\
\hline Self-agency & I myself am responsible for this situation & N/A & N/A \\
\hline Situational agency & $\begin{array}{l}\text { This situation was caused by circumstances } \\
\text { beyond human control } \\
\text { This situation is as it is due to } \\
\text { circumstances beyond anyone's control }\end{array}$ & $.856^{\mathrm{c}}$ & $.877^{\mathrm{c}}$ \\
\hline Control & $\begin{array}{l}\text { I feel that I can influence this situation } \\
\text { I am convinced that I can change this } \\
\text { situation }\end{array}$ & $.884^{\mathrm{c}}$ & $.834^{\mathrm{c}}$ \\
\hline
\end{tabular}

${ }^{a}$ Item is reverse-coded

${ }^{\mathrm{b}}$ Reported value is Cronbach's alpha

${ }^{\text {c}}$ Reported value is Spearman-Brown's correlation

\begin{tabular}{|c|c|c|}
\hline Scale & Items used in scale & Reliability $^{\mathrm{b}}$ \\
\hline Perceived ethics & $\begin{array}{l}\text { Ifeel that Zora... has good intentions, wants the best for me, is } \\
\text { malevolent, is mean }\end{array}$ & .705 \\
\hline Perceived affordances & $\begin{array}{l}\text { Ifeel that Zora is... intelligent, capable, skillful, handy, dumb }{ }^{\mathrm{a}} \text {, } \\
\text { clumsy }^{\mathrm{a}} \text {, incompetent }\end{array}$ & .806 \\
\hline Perceived aesthetics & Ifeel that Zora... looks pretty, is unattractive, is ugly, looks nice & .683 \\
\hline Perceived realism & $\begin{array}{l}\text { Ifeel that Zora ... appears natural, looks fake, looks real, looks } \\
\text { artificial }\end{array}$ & .663 \\
\hline Perceived relevance & Ifeel that Zora is... important, useless, useful, worthless & .653 \\
\hline Perceived valence & $\begin{array}{l}I \ldots \text { have positive expectations about Zora as a healthcare robot, } \\
\text { am reluctant about Zora in healthcare, expect to be } \\
\text { disappointed by Zora as a healthcare robot, look forward to } \\
\text { meet a healthcare robot such as Zora }\end{array}$ & .857 \\
\hline Perceived involvement & $\begin{array}{l}\text { Ifeel... good about Zora, involved with Zora, connected to Zora, } \\
\text { it's nice to talk to Zora }\end{array}$ & .836 \\
\hline Perceived distance & $\begin{array}{l}\text { Ifeel... it's annoying to talk to Zora, negative about Zora, that } \\
\text { Zora is remote to me, there's a distance between Zora and me }\end{array}$ & .652 \\
\hline Perceived use intentions & $\begin{array}{l}\text { I would... want to use Zora more frequently, want to come across } \\
\text { Zora in different places as well, dismiss Zora next time, ignore } \\
\text { Zora next time }\end{array}$ & .742 \\
\hline
\end{tabular}

${ }^{a}$ Item dropped from the scale based on results of PCA and reliability analysis

${ }^{b}$ All reported values are Cronbach's alpha 
Table 3 Overview of the robot perception measures and their reliabilities in study 2

\begin{tabular}{|c|c|c|}
\hline Scale & Items used in scale & Reliability ${ }^{b}$ \\
\hline Perceived ethics & $\begin{array}{l}\text { I feel that Zora... has good intentions }{ }^{\mathrm{a}} \text {, wants the best for me } \mathrm{e}^{\mathrm{a}} \text {, is malevolent, is mean, is trustworthy }{ }^{\mathrm{a}} \text {, } \\
\text { is dangerous, has questionable intentions }{ }^{\mathrm{a}} \text {, is insincere }{ }^{\mathrm{a}} \text {, is evil, is reliable }{ }^{\mathrm{a}}\end{array}$ & .772 \\
\hline Perceived affordances & I feel that Zora is... intelligent, capable, skillful, handy, dumb ${ }^{\mathrm{a}}$, clumsy ${ }^{\mathrm{a}}$, incompetent ${ }^{\mathrm{a}}$ & .765 \\
\hline Perceived aesthetics & $\begin{array}{l}\text { Ifeel that Zora... looks pretty, is unattractive, is ugly, looks nice, is unpleasant to look at }{ }^{\mathrm{a}} \text {, looks } \\
\text { horrible }^{\mathrm{a}} \text {, could have been designed better }{ }^{\mathrm{a}} \text {, could have looked prettier }\end{array}$ & 670 \\
\hline Perceived realism & $\begin{array}{l}\text { Ifeel that Zora } \ldots \text { appears natural, looks fake }{ }^{\mathrm{a}}, \text { looks real, looks artificial }{ }^{\mathrm{a}} \text {, looks realistic, looks lifelike, } \\
\text { looks authentic }{ }^{\mathrm{a}} \text {, looks unrealistic }{ }^{\mathrm{a}}\end{array}$ & .809 \\
\hline Perceived relevance & Ifeel that Zora is... important, useless, useful, worthless & .764 \\
\hline Perceived valence & $\begin{array}{l}I \ldots \text { have positive expectations about Zora as a healthcare robot, am reluctant about Zora in healthcare, } \\
\text { expect to be disappointed by Zora as a healthcare robot, look forward to meet a healthcare robot such } \\
\text { as Zora }\end{array}$ & .846 \\
\hline Perceived involvement & I feel... good about Zora, involved with Zora, connected to Zora, it's nice to talk to Zora & .822 \\
\hline Perceived distance & $\begin{array}{l}\text { Ifeel... it's annoying to talk to Zora }{ }^{\mathrm{a}} \text {, negative about Zora }{ }^{\mathrm{a}} \text {, that Zora is remote to me, there's a distance } \\
\text { between Zora and me, that I am indifferent about Zora, that Zora leaves me cold, it's irritating to talk } \\
\text { to Zora }^{\mathrm{a}}, \text { I'd rather stay away from robots such as Zora }^{\mathrm{a}}\end{array}$ & .795 \\
\hline Perceived use intentions & $\begin{array}{l}\text { I... want to use Zora more frequently, want to come across Zora in different places as well, would } \\
\text { dismiss Zora next time }{ }^{\mathrm{a}} \text {, would ignore Zora next time }{ }^{\mathrm{a}} \text {, wouldn't know what to do with a robot like } \\
\text { Zora, want nothing to do with a robot like Zora, do not want to see Zora again }{ }^{\mathrm{a}} \text {, have had enough of } \\
\text { Zora }^{\mathrm{a}}\end{array}$ & .829 \\
\hline
\end{tabular}

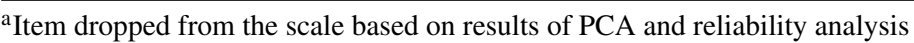

${ }^{b}$ All reported values are Cronbach's alpha

Table 4 Overview of coping strategy measures and their reliabilities in study 1 and 2

\begin{tabular}{|c|c|c|c|}
\hline Scale & Items used in scale & Reliability study $1^{\mathrm{a}}$ & Reliability study $2^{\mathrm{a}}$ \\
\hline Problem-focused & $\begin{array}{l}\text { I would... concentrate my efforts on doing something about the situation, take } \\
\text { action to try to make the situation better, try to come up with a strategy about } \\
\text { what to do }\end{array}$ & .814 & .793 \\
\hline Support & $\begin{array}{l}\text { I would try to get... emotional support from others, comfort and understanding } \\
\text { from someone, advice or help from other people about what to do, help and } \\
\text { advice from other people }\end{array}$ & .804 & .765 \\
\hline Emotion-focused & $\begin{array}{l}\text { I would... try to see it in a different light to make it seem more positive, try to } \\
\text { look for something good in what is happening, accept the reality of the fact } \\
\text { that it has happened, learn to live with it }\end{array}$ & .815 & .809 \\
\hline Humor & I would... make jokes about it, make fun of the situation & .818 & .767 \\
\hline Denial & I would... say to myself "this isn't real", refuse to believe that it has happened & .822 & .787 \\
\hline Self-distraction & $\begin{array}{l}\text { I would... turn to work or other activities to take my mind off things, do } \\
\text { something to think about it less such as go to the movies, watching TV, } \\
\text { reading, daydreaming, sleeping, or shopping }\end{array}$ & .713 & .768 \\
\hline Substance (ab)use & $\begin{array}{l}\text { I would... use alcohol or other drugs to make myself feel better, use alcohol or } \\
\text { other drugs to help me get through it }\end{array}$ & .955 & .922 \\
\hline Spiritual & I would... try to find comfort in my religion or spiritual beliefs, pray or meditate & .851 & .902 \\
\hline
\end{tabular}

PCA and reliability analyses showed that 7 items did not really fit any of the above scales, therefore, these 7 items are left out. These 7 items cover, amongst others, Carver's [29] subscales 'Venting', 'Behavioral disengagement', and 'Self-blame'

${ }^{a}$ All reported values are Cronbach's alpha

\section{Appendix 4: Overview Results RQ1, Step 1 and 2 (Study 1)}

To test effects of manipulated emotional state and coping potential on appraisals (and the appraisal of coping potential in particular), we ran a MANOVA analysis. We found sig- nificant multivariate effects for manipulated emotional state, Wilk's $\lambda=.19, F(5,84)=73.28, p<.001, \eta_{p}^{2}=.81$, for manipulated coping potential, Wilk's $\lambda=.72, F(5,84)=$ $6.54, p<.001, \eta_{p}^{2}=.28$, as well as for the interaction of both factors, Wilk's $\lambda=.76, F(5,84)=5.30, p<.001, \eta_{p}^{2}=.24$. 
Table 5 Means (M) and standard deviations (SD) for sad $(\mathrm{n}=46)$ and angry participants $(\mathrm{n}=46)$ on appraisals

\begin{tabular}{|c|c|c|c|c|c|c|}
\hline & \multicolumn{2}{|c|}{ Sad participants } & \multicolumn{2}{|c|}{ Angry participants } & \multirow[t]{2}{*}{$p$} & \multirow[t]{2}{*}{$F$} \\
\hline & $M$ & $S D$ & $M$ & $S D$ & & \\
\hline Coping potential & 2.23 & .75 & 3.33 & .89 & $<.001$ & 48.48 \\
\hline Control & 1.77 & .77 & 3.92 & .95 & $<.001$ & 172.71 \\
\hline Situational agency & 3.79 & 1.00 & 1.48 & .61 & $<.001$ & 208.57 \\
\hline Other-agency & 2.54 & 1.47 & 3.09 & 1.17 & .108 & 2.64 \\
\hline Self-agency & 1.37 & .77 & 3.00 & 1.17 & $<.001$ & 63.17 \\
\hline
\end{tabular}

Table 6 Means (M) and standard deviations (SD) for participants in the easy-to-cope-with $(\mathrm{n}=49)$ and hard-to-cope-with conditions (n $=43$ ) on the appraisals

\begin{tabular}{|c|c|c|c|c|c|c|}
\hline & \multicolumn{2}{|c|}{ Easy-to-cope-with } & \multicolumn{2}{|c|}{ Hard-to-cope-with } & \multirow[t]{2}{*}{$p$} & \multirow[t]{2}{*}{$F$} \\
\hline & $M$ & $S D$ & $M$ & $S D$ & & \\
\hline Coping potential & 2.97 & 1.01 & 2.56 & .92 & .001 & 10.75 \\
\hline Control & 2.98 & 1.52 & 2.70 & 1.21 & .002 & 9.71 \\
\hline Situational agency & 3.00 & 1.57 & 2.22 & 1.13 & .001 & 12.48 \\
\hline Other-agency & 2.39 & 1.40 & 3.30 & 1.12 & .002 & 10.71 \\
\hline Self-agency & 2.22 & 1.33 & 2.14 & 1.25 & .208 & 1.61 \\
\hline
\end{tabular}

Table 7 Regression results ( $\beta, p[95 \%$ CI lower limit; upper limit]) for appraisal scales on perceptions of the robot (Study 1)

\begin{tabular}{llllll}
\hline & Coping potential & Control & Situational agency & Other-agency & Self-agency \\
\hline Affordances & $-.07, .65(-.27 ; .17)$ & $-.09, .65(-.26 ; .16)$ & $-.06, .72(-. .19 ; .13)$ & $.08, .47(-.08 ; .17)$ & $.15, .33(-.09 ; .26)$ \\
Aesthetics & $-.06, .69(-.25 ; .16)$ & $.23, .26(-.09 ; .31)$ & $-.11, .48(-.20 ; .10)$ & $-.05, .64(-.14 ; .09)$ & $-.15, .34(-.24 ; .08)$ \\
Ethics & $-.15, .31(-.30 ; .10)$ & $.13, .53(-.13 ; .25)$ & $.15, .35(-.08 ; .21)$ & $.20, .09(-.01 ; .21)$ & $.14, .37(-.08 ; .22)$ \\
Relevance & $-.02, .88(-.20 ; .17)$ & $-.03, .87(-.20 ; .17)$ & $.17, .25(-.06 ; .22)$ & $.34, .002(.06 ; .27)$ & $.23, .11(-.03 ; .27)$ \\
Valence & $-.05, .73(-.35 ; .24)$ & $.28, .17(-.09 ; .48)$ & $.16, .32(-.11 ; .32)$ & $.10, .40(-.10 ; 24)$ & $-.10, .50(-.31 ; .15)$ \\
Realism & $.11, .46(-.14 ; .30)$ & $-.22, .29(-.33 ; .10)$ & $-.02, .90(-.17 ; .15)$ & $-.02, .86(-.14 ; .11)$ & $.25, .10(-.03 ; .32)$ \\
Involvement & $.02, .90(-.21 ; .24)$ & $.28, .15(-.06 ; .38)$ & $.14, .35(-.09 ; .25)$ & $.19, .09(-.02 ; .24)$ & $.11, .47(-.12 ; .25)$ \\
Distance & $-.06, .67(-.26 ; .17)$ & $-.11, .60(-.26 ; .15)$ & $-.13, .39(-.22 ; .09)$ & $-.16, .15(-.20 ; .03)$ & $-.05, .73(-.19 ; .14)$ \\
Use intentions & $-.02, .92(-.27 ; .24)$ & $.09, .65(-.19 ; .30)$ & $.14, .86(-.11 ; .27)$ & $.15, .19(-.05 ; .24)$ & $.10, .50(-.13 ; .27)$ \\
\hline
\end{tabular}

Univariate effects for manipulated emotional state showed significant effects on all appraisals (all $p s<.001, \eta_{p}^{2}>.35$ ) except other-agency $(n s)$. Specifically, sad participants appraised the situation as harder to cope with, harder to control, having more situational agency and having less selfagency than angry participants (see Table 5).

For manipulated coping potential, univariate tests showed significant effects on all appraisals (all $p s \leq .002, \eta_{p}^{2}>.09$ ) except self-agency $(n s)$. Participants who had read the easyto-cope-with scenario appraised their situation as easier to cope with and easier to control than did participants who had read the hard-to-cope-with scenario. Furthermore, participants in the easy-to-cope-with condition appraised more situational agency and less other-agency compared to participants in the hard-to-cope-with condition (see Table 6).
For the interaction of manipulated emotional state and coping potential, we found significant effects on the appraisal of control, $F(1,88)=10.89, p=.001, \eta_{p}^{2}=.11$, and the appraisal of situational agency, $F(1,88)=16.91, p<.001, \eta_{p}^{2}$ $=.16$. Within the participants that had read the sad emotional scenario, we did not find a big difference between the easyto-cope-with and the hard-to-cope-with conditions in terms of control; both appraised themselves to have relatively little control in the situation $(M=1.76, S D=.76$ and $M=1.79$, $S D=.79$ respectively). Within the angry condition, however, we found a bigger difference: Participants that had read the easy-to-cope-with scenario appraised much more personal control of their situation $(M=4.48, S D=3.42)$ compared to participants that had read the hard-to-cope-with scenario $(M$ $=3.42, S D=.97$ ). For the appraisal of situational agency, a reverse pattern was found. Angry participants appraised rela- 
tively little situational agency, regardless of whether they had read the easy-to-cope-with $(M=1.43, S D=.60)$ or the hardto-cope-with scenario $(M=1.52, S D=.63)$. The difference was larger amongst the sad participants: Those in the easy-tocope-with condition appraised much more situational agency $(M=4.28, S D=.68)$ than those in the hard-to-cope-with condition $(M=3.11, S D=.99)$.

To test whether the appraisal scales affects perceptions of the robot, we ran a series of regression analyses. Results showed that only the appraisal of other-agency affected the perception of the robot's relevance, $b\left(S E_{b}\right)=.17(.05), \beta=$ $.34, p=.002,95 \%$ CI $[.06, .27]$. All other results were nonsignificant (see Table 7).

\section{Appendix 5: Overview Results H2 (Study 1)}

We used a mixed-design MANOVA with manipulated emotional state and coping potential as between-subject factors, and the 8 coping strategies as within-subjects factor. Within-subjects effects were found for coping strategy, ${ }^{6}$ $F(5.25,509.67)=100.09, p<.001, \eta_{p}^{2}=.51$, and the interaction of coping strategy and manipulated emotional state, ${ }^{7}$ $F(5.25,509.67)=19.07, p<.001, \eta_{p}^{2}=.16$. The interaction of coping strategy and manipulated coping potential was not found, $F(5.25,509.67)=.89, p=.49, \eta_{p}^{2}=.01$, nor the three-way interaction of coping strategy, manipulated emotional state, and manipulated coping potential, $F(5.25$, $509.67)=1.66, p=.14, \eta_{p}^{2}=.02$. Below we present some of the univariate results. For a full overview of all results and exact $p$-values, interested readers are referred to the OSF project page, where the data and analysis scripts are available (https://osf.io/an5gr/).

Within-subject effects of coping strategy using pairwise comparisons using Bonferroni correction for multiple comparisons showed that the support and problem-focused coping strategies were both used more often than the other strategies $(p s<.005)$, but did not significantly differ from one another in usage ( $p=1.00$; see also Table 8 ). The coping strategies of denial, humor, substance (ab)use, and spiritual coping were used less often than the other strategies ( $p s<.001)$, but also not compared to one another $(p s=1.00)$. The emotion-focused coping strategy scored in between the other coping strategies, but significantly differed from all of them $(p s<.005)$.

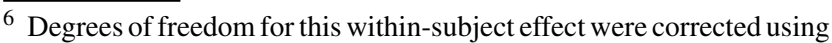
the Greenhouse-Geisser correction because the assumption of sphericity was violated.

7 Degrees of freedom for this within-subject effect were corrected using the Greenhouse-Geisser correction because the assumption of sphericity was violated.
}

Table 8 Descriptive statistics for use of coping strategies

\begin{tabular}{|c|c|c|}
\hline & & Mean $(S D)$ \\
\hline \multirow[t]{3}{*}{ Problem-focused coping } & Total & $3.88(.93)$ \\
\hline & Sad (manipulated) & $3.30(.85)$ \\
\hline & Angry (manipulated) & $4.47(.56)$ \\
\hline \multirow[t]{3}{*}{ Emotion-focused coping } & Total & $2.92(1.01)$ \\
\hline & Sad (manipulated) & $3.19(.98)$ \\
\hline & Angry (manipulated) & $2.65(.99)$ \\
\hline \multirow[t]{3}{*}{ Support coping } & Total & $3.98(.85)$ \\
\hline & Sad (manipulated) & $3.83(.96)$ \\
\hline & Angry (manipulated) & $4.12(.70)$ \\
\hline \multirow[t]{3}{*}{ Humor coping } & Total & $1.86(1.06)$ \\
\hline & Sad (manipulated) & $1.48(.93)$ \\
\hline & Angry (manipulated) & $2.24(1.07)$ \\
\hline \multirow[t]{3}{*}{ Denial coping } & Total & $1.97(1.08)$ \\
\hline & Sad (manipulated) & $2.34(1.27)$ \\
\hline & Angry (manipulated) & $1.59(.68)$ \\
\hline \multirow[t]{3}{*}{ Self-distraction coping } & Total & $3.45(1.07)$ \\
\hline & Sad (manipulated) & $3.97(.80)$ \\
\hline & Angry (manipulated) & $2.92(1.06)$ \\
\hline \multirow[t]{3}{*}{ Substance (ab)use coping } & Total & $1.74(1.07)$ \\
\hline & Sad (manipulated) & $2.01(1.16)$ \\
\hline & Angry (manipulated) & $1.46(.89)$ \\
\hline \multirow[t]{3}{*}{ Spiritual coping } & Total & $1.90(1.26)$ \\
\hline & Sad (manipulated) & $2.34(1.44)$ \\
\hline & Angry (manipulated) & $1.44(.82)$ \\
\hline
\end{tabular}

Moreover, we found in the pairwise comparisons for the interaction of coping strategy and manipulated emotional state that angry and sad participants differed significantly in their use of all coping strategies (all $p s<.02$ ) except for the support coping strategy. This was qualified by a between-subject effect of emotional state: Compared to sad participants, angry participants used significantly more problem-focused and humorous coping strategies and fewer emotion-focused, denial, distraction, substance ( $a b)$ use, and spiritual coping strategies (all $p s<.02$ ).

\section{Appendix 6: Overview Results H3 Problem-Focused and Emotion-Focused Coping Strategies (Studies 1 and 2)}

See Table 9. 
Table 9 Regression results of problem-focused and emotion-focused coping strategies ${ }^{1}$ on perceptions of robot Zora from Studies 1 and 2

\begin{tabular}{|c|c|c|c|c|c|c|c|c|}
\hline \multirow{3}{*}{ Perception } & \multicolumn{4}{|c|}{ Study 1} & \multicolumn{4}{|c|}{ Study 2} \\
\hline & \multicolumn{2}{|c|}{ Problem-focused coping } & \multicolumn{2}{|c|}{ Emotion-focused coping } & \multicolumn{2}{|c|}{ Problem-focused coping } & \multicolumn{2}{|c|}{ Emotion-focused coping } \\
\hline & $\beta$ & $p(95 \% \mathrm{CI})$ & B & $p(95 \% \mathrm{CI})$ & $\beta$ & $p(95 \% \mathrm{CI})$ & ß & $p(95 \% \mathrm{CI})$ \\
\hline Ethics & .20 & $.09(-.02 ; .30)$ & -.18 & $.13(-.26 ; .03)$ & .01 & $.92(-.11 ; .12)$ & .21 & $.07(-.01 ; .19)$ \\
\hline Affordances & .09 & $.45(-.11 ; .26)$ & -.14 & $.25(-.26 ; .07)$ & .17 & $.15(-.05 ; .32)$ & .14 & $.20(-.05 ; .26)$ \\
\hline Aesthetics & .13 & $.29(-.09 ; .28)$ & -.08 & $.52(-.21 ; .11)$ & .04 & $.71(-.13 ; .20)$ & .07 & $.56(-.10 ; .18)$ \\
\hline Realism & .17 & $.17(-.06 ; .32)$ & -.14 & $.24(-.27 ; .07)$ & -.05 & $.66(-.26 ; .16)$ & .15 & $.18(-.06 ; .30)$ \\
\hline Relevance & .02 & $.87(-.15 ; .18)$ & -.17 & $.15(-.26 ; .04)$ & -.04 & $.74(-.20 ; .14)$ & .27 & $.02(.03 ; .32)$ \\
\hline Valence & .04 & $.73(-.21 ; .29)$ & -.03 & $.83(-.25 ; .20)$ & -.02 & $.85(-.25 ; .21)$ & .18 & $.12(-.04 ; .35)$ \\
\hline Involvement & .18 & $.14(-.05 ; .35)$ & -.17 & $.15(-.31 ; .05)$ & -.08 & $.48(-.26 ; .13)$ & .01 & $.93(-.16 ; .17)$ \\
\hline Distance & -.22 & $.07(-.34 ; .01)$ & .10 & $.37(-.09 ; .23)$ & .08 & $.53(-.15 ; .29)$ & -.03 & $.81(-.21 ; .16)$ \\
\hline Use Intentions & .25 & $.04(.01 ; .44)$ & -.12 & $.31(-.29 ; .09)$ & -.04 & $.76(-.28 ; .20)$ & .21 & $.08(-.02 ; .39)$ \\
\hline
\end{tabular}

${ }^{1}$ Results are only presented for problem-focused and emotion-focused coping strategies, even though the other six coping strategies were also included in the analyses. Interested readers may look up all results via the available data and analysis scripts on the OSF project page (https://osf. io/an5gr/)

\section{Appendix 7: Overview Results RQ1, Step 1 and 2 (Study 2)}

The MANOVA showed significant multivariate effects for manipulated emotional state, Wilk's $\lambda=.24, F(5,102)=$ $65.53, p<.001, \eta_{p}^{2}=.76$, for manipulated coping potential, Wilk's $\lambda=.78, F(5,102)=5.73, p<.001, \eta_{p}^{2}=.22$, as well as for the interaction of both factors, Wilk's $\lambda=.87, F(5,102)$ $=3.13, p=.01, \eta_{p}^{2}=.13$.

For manipulated emotional state we found that the univariate effects were similar to those in Study 1. Significant differences were found between the sad and angry participants in terms of all appraisals (all $p s<.001, \eta_{p}^{2} \geq .23$ ) except for the appraisal of other-agency $(n s)$. Sad participants appraised their situation as harder to cope with, harder to control, having more situational agency and having less self-agency compared to angry participants (see Table 10 below).

Table 10 Means (M) and standard deviations (SD) for sad $(\mathrm{n}=55)$ and angry participants $(n=55)$ on the appraisals of coping potential, control, situational agency, and self-agency

\begin{tabular}{llrllllll}
\hline & \multicolumn{2}{l}{$\begin{array}{l}\text { Sad } \\
\text { participants }\end{array}$} & & \multicolumn{2}{l}{$\begin{array}{l}\text { Angry } \\
\text { participants }\end{array}$} & $p$ value & $\eta_{p}^{2}$ \\
\cline { 2 - 3 } & $M$ & $S D$ & & $M$ & $S D$ & & \\
\hline Coping potential & 2.48 & .70 & 3.49 & .85 & $<.001$ & .35 \\
Control & 2.20 & .91 & 4.07 & .68 & $<.001$ & .59 \\
Situational agency & 3.73 & 1.12 & 1.45 & .68 & $<.001$ & .61 \\
Other-agency & 2.93 & 1.48 & 3.35 & 1.19 & .223 & .01 \\
Self-agency & 1.55 & .90 & 2.71 & 1.21 & $<.001$ & .23 \\
\hline
\end{tabular}

Univariate effects for the manipulation of coping potential showed significant effects on appraised coping potential, $F(1,106)=22.01, p<.001, \eta_{p}^{2}=.17$, and appraised situational agency, $F(1,106)=5.83, p=.02, \eta_{p}^{2}=.05$. No differences were found between the coping potential conditions in terms of appraised control, other-agency, and self-agency (all three $n s$ ). Specifically, participants who had read the easy-to-cope-with scenario were found to appraise their situation as easier to cope with and having more situational agency than participants who had read the hardto-cope-with scenario (see Table 11 below).

For the interaction of manipulated emotional state and coping potential, we found significant effects on the appraisal of situational agency, $F(1,106)=7.33, p<.01, \eta_{p}^{2}=.07$, and the appraisal of other-agency, $F(1,106)=6.95, p=$ $.01, \eta_{p}^{2}=.06$. Within the participants that had read the sad emotional scenario, we found that the participants in the easyto-cope-with condition appraised their situation as having more situational agency $(M=4.08, S D=1.13)$ than the hard-

Table 11 Means (M) and standard deviations (SD) for participants in the easy-to-cope-with $(\mathrm{n}=62)$ and hard-to-cope-with conditions $(\mathrm{n}=$ 48 ) on the appraisals of coping potential and situational agency

\begin{tabular}{llrllllll}
\hline & \multicolumn{2}{l}{$\begin{array}{l}\text { Easy-to- } \\
\text { cope-with }\end{array}$} & & \multicolumn{2}{l}{$\begin{array}{l}\text { Hard-to- } \\
\text { cope-with }\end{array}$} & $p$ value & $\eta_{p}^{2}$ \\
\cline { 2 - 3 } & $M$ & $S D$ & & $M$ & $S D$ & & \\
\hline Coping potential & 3.23 & .90 & & 2.66 & .87 & $<.001$ & .17 \\
Control & 3.18 & 1.27 & 3.08 & 1.19 & .133 & .02 \\
Situational agency & 2.84 & 1.62 & 2.27 & 1.18 & .017 & .05 \\
Other-agency & 2.97 & 1.34 & 3.35 & 1.35 & .143 & .02 \\
Self-agency & 2.15 & 1.14 & 2.10 & 1.31 & .542 & .004 \\
\hline
\end{tabular}


Table 12 Regression results ( $\beta, p[95 \%$ CI lower limit; upper limit]) for appraisal scales on perceptions of the robot (Study 2)

\begin{tabular}{llllll}
\hline & Coping potential & Control & Situational agency & Other-agency & Self-agency \\
\hline Affordances & $-.16, .20(-.32 ; .07)$ & $.06, .66(-.13 ; .21)$ & $-.07, .57(-.16 ; .09)$ & $.06, .60(-.08 ; .14)$ & $-.02, .89(-.16 ; .14)$ \\
Aesthetics & $-.11, .35(-.24 ; .09)$ & $.10, .48(-.09 ; .19)$ & $-.08, .55(-.14 ; .07)$ & $-.14, .20(-.16 ; .03)$ & $-.09, .49(-.17 ; .08)$ \\
Ethics & $.11, .35(-.06 ; .17)$ & $.04, .77(-.09 ; .12)$ & $.04, .74(-.06 ; .09)$ & $-.004, .97(-.07 ; .07)$ & $-.21, .08(-.17 ; .01)$ \\
Relevance & $-.03, .81(-.19 ; .15)$ & $-.01, .97(-.15 ; .15)$ & $.22, .08(-.01 ; .21)$ & $.08, .43(-.06 ; .14)$ & $.15, .22(-.05 ; .21)$ \\
Valence & $.13 . .28(-.10 ; .35)$ & $-.08, .56(-.25 ; .14)$ & $-.01, .96(-.15 ; .14)$ & $-.08, .45(-.18 ; .08)$ & $-.24, .05(-.34 ;-.001)$ \\
Realism & $.09, .48(-.13 ; .28)$ & $-.21, .15(-.31 ; .05)$ & $-.10, .43(-.18 ; .08)$ & $-.05, .64(-.15 ; .09)$ & $.10, .43(-.10 ; .22)$ \\
Involvement & $-.10, .40(-.27 ; .11)$ & $.05, .73(-.14 ; .20)$ & $-.02, .87(-.13 ; .11)$ & $.19, .07(-.01 ; .22)$ & $-.04, .77(-.17 ; .12)$ \\
Distance & $.08, .51(-.14 ; .29)$ & $.06, .70(-.15 ; .23)$ & $.16, .19(-.05 ; .23)$ & $.08, .43(-.08 ; .18)$ & $.08, .49(-.11 ; .22)$ \\
Use intentions & $-.09, .49(-.32 ; .15)$ & $.16, .26(-.09 ; .33)$ & $.12, .33(-.08 ; .23)$ & $.02, .89(-.13 ; .15)$ & $-.06, .64(-.23 ; .14)$ \\
\hline
\end{tabular}

to-cope-with condition $(M=3.20, S D=.90)$. Within the angry condition, however, we found that there was not much of a difference between participants in the easy-to-cope-with $(M=1.43, S D=.66)$ and those in the hard-to-cope-with conditions $(M=1.48, S D=.71)$. For the appraisal of otheragency, we found that angry participants also did not differ much (easy-to-cope-with: $M=3.48, S D=.99$; hard-tocope-with: $M=3.19, S D=1.39$ ), while the difference was somewhat bigger (and reversed) amongst participants in the sad condition (easy-to-cope-with: $M=2.52, S D=1.46$; hard-to-cope-with: $M=3.55, S D=1.30)$.

To test whether the appraisal scales (and the appraisal of coping potential in particular) affected perceptions of robot Zora, we ran a series of regressions analyses (one for each of the perception measures). Results showed that only the appraisal of self-agency affected the perception of the robot's valence, $b\left(S E_{b}\right)=-.17(.09), \beta=-.24, p=.049,95 \% \mathrm{CI}$ $[-.34,-.001]$. All other results were non-significant (see Table 12).

\section{Appendix 8: Overview Results H2 (Study 1)}

To test $\mathrm{H} 2$, predicting the effect of manipulated coping potential on the use of problem-focused, emotion-focused, and related coping strategies, we used a mixed-design MANOVA. We entered manipulated emotional state and manipulated coping potential as between-subject factors, and the 8 coping strategies (including problem-focused and emotionfocused coping strategies) as within-subject factors. For a full overview of all results and exact $p$-values, interested readers are referred to the OSF project page where data and analysis scripts are found (https://osf.io/an5gr/).

Similar to results of study 1 , we found within-subjects effects for coping strategy, ${ }^{8} F(5.596,593.227)=140.43$,

\footnotetext{
${ }^{8}$ Degrees of freedom for this analysis were corrected using the Greenhouse-Geisser correction because the assumption of sphericity was violated.
}

Table 13 Descriptive statistics for use of coping strategies

\begin{tabular}{|c|c|c|}
\hline & & Mean $(S D)$ \\
\hline \multirow[t]{3}{*}{ Problem-focused coping } & Total & $3.90(.88)$ \\
\hline & High coping potential & $3.94(.85)$ \\
\hline & Low coping potential & $3.84(.94)$ \\
\hline \multirow[t]{3}{*}{ Emotion-focused coping } & Total & $2.98(1.02)$ \\
\hline & High coping potential & $3.19(1.07)$ \\
\hline & Low coping potential & $2.72(.91)$ \\
\hline \multirow[t]{3}{*}{ Support coping } & Total & $3.94(.78)$ \\
\hline & High coping potential & $3.75(.83)$ \\
\hline & Low coping potential & $3.96(.70)$ \\
\hline \multirow[t]{3}{*}{ Humor coping } & Total & $1.92(1.06)$ \\
\hline & High coping potential & $2.02(1.02)$ \\
\hline & Low coping potential & $1.79(1.11)$ \\
\hline \multirow[t]{3}{*}{ Denial coping } & Total & $1.93(.91)$ \\
\hline & High coping potential & $1.76(.88)$ \\
\hline & Low coping potential & $2.15(.91)$ \\
\hline \multirow[t]{3}{*}{ Self-distraction coping } & Total & $3.48(1.06)$ \\
\hline & High coping potential & $3.40(1.07)$ \\
\hline & Low coping potential & $3.59(1.06)$ \\
\hline \multirow[t]{3}{*}{ Substance (ab)use coping } & Total & $1.52(.87)$ \\
\hline & High coping potential & $1.52(.94)$ \\
\hline & Low coping potential & $1.53(.77)$ \\
\hline \multirow[t]{3}{*}{ Spiritual coping } & Total & $1.90(1.25)$ \\
\hline & High coping potential & $2.09(1.38)$ \\
\hline & Low coping potential & $1.67(1.02)$ \\
\hline
\end{tabular}

$p<.001, \eta_{p}^{2}=.57$, and the interaction of coping strategy use and manipulated emotional state ${ }^{5}, F(5.596,593.227)=$ 22.78, $p<.001, \eta_{p}^{2}=.18$. Most important for $\mathrm{H} 2$ however, we found a significant interaction effect of coping strategy use and manipulated coping potential, $F(5.596,593.227)^{5}=$ $3.81, p=.001, \eta_{p}^{2}=.04$. Pairwise comparisons (using Bonferroni correction for multiple comparisons) showed that this interaction was qualified by significant differences between the high and low coping potential conditions for only two 
coping strategies: denial and emotion-focused coping. Participants in the high coping potential condition used denial to cope with the emotional situation significantly less often $(M=1.76, S D=.88)$ compared to the low coping potential participants $(M=2.15, S D=.91, p=.012)$. Results showed that emotion-focused coping was used more often by participants in the high coping potential condition $(M=3.19, S D$ $=1.07)$ than by their low coping potential counterparts $(M$ $=2.72, S D=.91, p=.012$ ). This effect contrasted $\mathrm{H} 2$, in which we expected that emotion-focused coping strategies would be used primarily in situations that would be hard to cope with (ergo, low coping potential). We also hypothesized that high coping potential would be related to the use of the problem-focused coping strategy, but pairwise comparisons showed no such effect $(p=.102)$. Furthermore, the overall between-subjects effect for manipulated coping potential was not significant. See Table 13 for more details for the other coping strategies.

For the within-subjects effect of coping strategy, pairwise comparisons showed the same pattern ${ }^{9}$ as in Study 1 (see also Table 13). Bonferroni-corrected pairwise comparisons for the interaction of coping strategy emotional state showed that angry and sad participants differed in their use of all coping strategies $(p s<.03)$ except for the support and spiritual coping strategies $\left(p=.727\right.$ and $p=.160$, respectively). ${ }^{10}$

\section{References}

1. Spekman MLC, Konijn EA, Hoorn JF (2018) Perceptions of healthcare robots as a function of emotion-based coping: the importance of coping appraisals and coping strategies. Comput Hum Behav 85:308-318. https://doi.org/10.1016/j.chb.2018.03.043

2. Spekman MLC, Konijn EA, Hoorn JF (2018). Belief in emotional coping ability affects what you see in a robot, not the emotions as such. Dissertation, Vrije Universiteit Amsterdam, Amsterdam

3. World Health Organization (2015) World report on ageing and health. http://apps.who.int/iris/bitstream/10665/186463/1/978924 0694811_eng.pdf. Accessed 24 May 2019

4. Broadbent E, Stafford R, MacDonald B (2009) Acceptance of healthcare robots for the older population: review and future directions. Int J Soc Robot 1:319-330. https://doi.org/10.1007/s12369009-0030-6

5. De Graaf MMA, Ben Allouch S, Klamer T (2015) Sharing a life with Harvey: exploring the acceptance of and relationship-building with a social robot. Comput Hum Behav 43:1-14. https://doi.org/ 10.1016/j.chb.2014.10.030

\footnotetext{
$\overline{9}$ The support and problem-focused coping strategies were used more often than the other strategies $(p s<.01)$, and the denial, humor, substance (ab)use, and spiritual coping strategies were used less often compared to the other strategies $(p s<.001)$.

10 The interaction was qualified by a between-subjects effect for emotional state, suggesting that sad participants used more emotion-focused, more denial, more distraction, and more substance (ab)use coping strategies, and less humor and problem-focused coping strategies compared to their angry counterparts.
}

6. Hoorn JF, Konijn EA, Germans DM, Burger S, Munneke A (2015) The in-between machine: the unique value proposition of a robot or why we are modelling the wrong things. In: Loiseau S, Filipe J, Duval B, Van den Herik J (eds) Proceedings of the 7th international conference on agents and artificial intelligence (ICAART). Scitepress, Lisbon, pp 464-469

7. Van Kemenade M, Konijn EA, Hoorn JF (2015) Robots humanize care: Moral concerns versus witnessed benefits for the elderly. In: Verdier C, Bienkiewicz M, Fred A, Gamboa H, Elias D (eds) Proceedings of the 8th international conference on health informatics (HEALTHINF). Scitepress, Lisbon, pp 648-653. https://doi.org/1 $0.5220 / 0005287706480653$

8. Stafford RQ, MacDonald BA, Jayawardena C, Wegner DM, Broadbent E (2014) Does the robot have a mind? Mind perception and attitudes towards robots predict use of an eldercare robot. Int J Soc Robot 6:17-32. https://doi.org/10.1007/s12369-013-0186-y

9. Broadbent E, Kuo IH, Lee YI, Rabindran J, Kerse N, Stafford R, MacDonald BA (2010) Attitudes and reactions to a healthcare robot. Telemed eHealth 16:608-613. https://doi.org/10.1089/tmj.2 009.0171

10. Frijda NH (2007) The laws of emotion. Lawrence Erlbaum Associates, Mahwah

11. Lerner JS, Keltner D (2000) Beyond valence: towards a model of emotion-specific influences on judgment and choice. Cogn Emotion 14:473-493. https://doi.org/10.1080/026999300402763

12. Lerner JS, Keltner D (2001) Fear, anger, and risk. J Pers Soc Psychol 81:146-159. https://doi.org/10.1037/0022-3514.81.1.146

13. Ellsworth PC, Scherer KR (2003) Appraisal processes in emotion. In: Davidson RJ, Scherer KR, Goldsmith HH (eds) Handbook of affective sciences. Oxford University Press, New York, pp 572-595

14. Lazarus RS (1999) Stress and emotion: a new synthesis. Springer, New York

15. Lazarus RS (2001) Relational meaning and discrete emotions. In: Scherer KR, Schorr A, Johnstone T (eds) Appraisal processes in emotion: theory, methods, research. Oxford University Press, New York, pp 37-67

16. Chiavarino C, Rabellino D, Ardito RB, Cavallero E, Palumbo Let al (2012) Emotional coping is a better predictor of cardiac prognosis than depression and anxiety. J Psychosom Res 73:473-475. https:// doi.org/10.1016/j.jpsychores.2012.10.002

17. Glanz K, Schwartz MD (2008) Stress, coping, and health behavior. In: Glanz K, Rimer BK, Viwanath K (eds) Health behavior and health education: theory, research, and practice. Jossey-Bass, San Francisco, pp 211-236

18. Lazarus RS, Folkman S (1984) Stress, appraisal, and coping. Springer, New York

19. Olsson CA, Bond L, Johnson MW, Forer DL, Boyce MF, Sawyer SM (2003) Adolescent chronic illness: a qualitative study of psychosocial adjustment. Ann Acad Med Singap 32:43-50

20. Harmon-Jones E, Sigelman JD, Bohlig A, Harmon-Jones C (2003) Anger, coping, and frontal cortical activity: the effect of coping potential on anger-induced left frontal activity. Cogn Emotion 17:1-24. https://doi.org/10.1080/02699930143000635

21. Lowe R, Vedhara K, Bennet P et al (2003) Emotion-related primary and secondary appraisals, adjustment and coping: associations in women awaiting breast disease diagnosis. Br J Health Psychol 8:377-391. https://doi.org/10.1348/135910703770238257

22. Green JD, Sedikides C (1999) Affect and self-focused attention revisited: the role of affect orientation. Pers Soc Psychol Bull 25:104-119. https://doi.org/10.1177/0146167299025001009

23. Dix A, Finlay J, Abowd GD, Beale R (2004) Human-computer interaction, 3rd edn. Pearson, Essex

24. Priebe S, Huxley P, Knight S, Evans S (1999) Application and results of the Manchester Short Assessment of Quality of Life (Mansa). Int J Soc Psychiatry 45:7-12. https://doi.org/10.1177/0 02076409904500102 
25. Lavoie JAA (2013) Eye of the beholder: perceived stress, coping style, and coping effectiveness among discharged psychiatric patients. Arch Psychiatr Nurs 27:185-190. https://doi.org/10.101 6/j.apnu.2013.02.004

26. Smith CA, Ellsworth PC (1985) Patterns of cognitive appraisal in emotion. J Pers Soc Psychol 48:813-838. https://doi.org/10.1037/ 0022-3514.48.4.813

27. Van Vugt HC, Konijn EA, Hoorn JF, Veldhuis J (2009) When too heavy is just fine: creating trustworthy e-health advisors. Int J Hum Comput Stud 67:571-583. https://doi.org/10.1016/j.ijhcs.2009.02. 005

28. Eisinga R, Te Grotenhuis M, Pelzer B (2012) The reliability of a two-item scale: Person, Cronbach, or Spearman-Brown? Int J Public Health 58:637-642. https://doi.org/10.1007/s00038-012-0 416-3

29. Carver CS (1997) You want to measure coping but your protocol's too long: consider the Brief COPE. Int J Behav Med 4:92-100. https://doi.org/10.1207/s15327558ijbm0401_6

30. Gross JJ, John OP (2003) Individual differences in two emotion regulation processes: implication for affect, relationships, and wellbeing. J Pers Soc Psychol 85:348-362. https://doi.org/10.1037/00 22-3514.85.2.348

31. Westermann R, Spies K, Stahl G, Hesse FW (1996) Relative effectiveness and validity of mood induction procedures: a metaanalysis. Eur J Soc Psychol 26:557-580

32. Salas CE, Radovic D, Turnbull OH (2012) Inside-out: comparing internally generated and externally generated basic emotions. Emotion 12:568-578

33. Hoffmann L, Krämer NC (2013) Investigating the effects of physical and virtual embodiment in task-oriented and conversational contexts. Int J Hum Comput Stud 71:763-774. https://doi.org/10. 1016/j.ijhcs.2013.04.007

34. Jung Y, Lee KM (2004) Effects of physical embodiment on social presence of social robots. In: Proc PRESENCE 2004, pp 80-87

35. Powers A, Kiesler S, Fussell S, Torrey C (2007) Comparing a computer agent with a humanoid robot. In: Proc ACM/IEEE int conf hum-robot interact, pp 145-152. https://doi.org/10.1145/1228716. 1228736

36. Venkatesh V, Thong JYL, Xu X (2012) Consumer acceptance and use of information technology: extending the unified theory of acceptance and use of technology. MIS Q 36:157-178. https://doi. org/10.2307/41410412

37. Lazarus RS (2006) Emotions and interpersonal relationships: toward a person-centered conceptualization of emotions and coping. J Pers 74:9-46. https://doi.org/10.1111/j.1467-6494.2005.003 68. $\mathrm{x}$

Publisher's Note Springer Nature remains neutral with regard to jurisdictional claims in published maps and institutional affiliations.
Marloes L. C. Spekman is a Communication Scientist / Media Psychologist primarily working on emotions, and prosocial and health behavior. She obtained her $\mathrm{PhD}$ in 2018 from the Vrije Universiteit (Dept. of Communication Science) on the topic of emotional transfer in (prospective) users in interaction with social, humanoid robots. Her work with robot Alice was featured in the award-winning documentary Alice Cares. She currently works as postdoctoral researcher at the Dept. of Sociology at the Vrije Universiteit Amsterdam and the Dept. of Donor Studies at Sanquin Research in Amsterdam.

Elly A. Konijn is full Professor in Media Psychology at the Department of Communication Science, Vrije Universiteit Amsterdam. Building on her multidisciplinary background in psychology, media studies, and computer science, she initiated and developed the unique graduate and research program in Media Psychology Amsterdam. Her research focuses on three interconnected lines: (i) relating to media figures, virtual humans, and social robots; (ii) emotions and media-based reality perceptions (iii) media use among adolescents. Konijn's research work has been published in major scientific journals, books, and edited volumes in the field, and has been presented in professional documentaries, invited lectures, and media appearances. She has served as chair of the Information Systems division of the International Communication Association and editor of MediaPsychology. Together with Johan Hoorn, Konijn led the SELEMCA research program on social robots resulting in an internationally renowned documentary Alice Cares (Burger \& Doolaard, 2015), showing how three elderly ladies become attached to a humanoid social robot (https://www.doxy.nl/en/ film/ik-ben-alice).

Johan F. Hoorn is a full professor of Social Robotics at The Hong Kong Polytechnic University, Dept. of Computing and School of Design. Johan holds a Ph.D. (2006) in Computer Science from Vrije Universiteit Amsterdam as well as a Ph.D. (1997) in General and Comparative Literature from the same university. He has $200+$ publications in journals, conference proceedings, and as books and book chapters. His work on social robotics and older adults became internationally renowned though the documentary Alice Cares (https://en.m. wikipedia.org/wiki/Alice_Cares). His current research interests focus on the theory of emotion, creativity, reality perception, and moral reasoning, implemented in artificial agents and social robots. 